\title{
Magnetization of polar ice: a measurement of terrestrial dust and extraterrestrial fallout
}

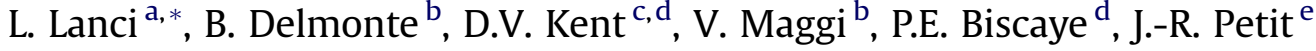

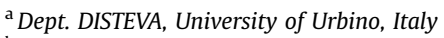 \\ ${ }^{\mathrm{b}}$ Dipartimento di Scienze Ambientali, University of Milano-Bicocca, Milano, Italy \\ ${ }^{\mathrm{C}}$ Department of Earth \& Planetary Sciences, Rutgers University, Piscataway, NJ, USA \\ ${ }^{\mathrm{d}}$ Lamont-Doherty Earth Observatory, Palisades, NY, USA \\ e Laboratoire de Glaciologie et de Géophysique de l'Environnement, Saint Martin d'Hères, France
}

\section{A R T I C L E I N F O}

\section{Article history:}

Received 10 August 2011

Received in revised form

27 November 2011

Accepted 29 November 2011

Available online 24 December 2011

\section{Keywords:}

Rock-magnetism

Ice cores

Atmospheric dust

Meteoric smoke

Micrometeorites

\begin{abstract}
A B S T R A C T
Laboratory-induced remanent magnetization of polar ice constitutes a measurement of the magnetization carried by the ferromagnetic dust particles in the ice. This non-destructive technique provides a novel kind of information on the dust deposited on the surface of polar ice sheets. Measurements made on ice samples from Greenland (North GRIP ice core) and Antarctica (Vostok and EPICA-Dome C ice cores) allowed the recognition of a fraction of magnetic minerals in ice whose concentration and magnetic properties are directly related to that of insoluble dust. The source of this fraction of magnetic minerals thus appears closely related to terrestrial dust transport and deposition and its magnetic properties are informative of the dust provenance areas. The rock-magnetic properties of the dust may reflect distinct changes of dust source areas from glacial to interglacial periods in agreement with and adding further information to the isotopic $\left({ }^{87} \mathrm{Sr} /{ }^{86} \mathrm{Sr}\right.$ and $\left.{ }^{143} \mathrm{Nd} /{ }^{144} \mathrm{Nd}\right)$ analyses. A second magnetic fraction consists of particles of nanometric size, which are superparamagnetic at freezer temperature and whose concentration is independent of the mass of aerosol dust found in the ice. The source of these nanometric-sized magnetic particles is ascribed to fallout of "meteoric smoke" and their concentration in ice was found to be compatible with the extraterrestrial fallout inferred from Ir concentrations. The diameter of the smoke particles as inferred from magnetic measurements is in the range of about 7-20 nm.
\end{abstract}

(c) 2011 Elsevier Ltd. All rights reserved.

\section{Introduction}

Polar ice sheets are among the most detailed and direct archive of atmospheric aerosol, providing a record of mineral dust which is of aeolian origin and mostly windblown from continental areas over very long distances. The concentration of dust entrapped in polar ice, its grain size and physical properties, vary over geological time scales as modulated by synergic factors directly or indirectly related to climatic conditions. Dust flux and particle size are probably controlled by a combination of factors such as source-area conditions and extent, dust transport (advection time and life-time), and accumulation of snow over polar areas.

The concentration of mineral dust is extremely low in Greenland and Antarctic ice. Glacial/interglacial changes in dust concentration recorded in ice cores range from about $1 \times 10^{4} \mathrm{ppb}-50 \mathrm{ppb}$ in the interior of Greenland (e.g. Steffensen, 1997; Svensson et al., 2000;

\footnotetext{
* Corresponding author.

E-mail address: luca.lanci@uniurb.it (L. Lanci).
}

Ruth et al., 2003) and from up to 700-800 ppb to about $10 \mathrm{ppb}$ in central East Antarctica (e.g. Petit et al., 1999; Lambert et al., 2008). Thus, dust concentration decreased by a factor of 10-100 from colder to warmer climate periods (glacial/interglacial periods); most of the increase in dust concentration in Antarctica during glacial periods with respect to Holocene climate has been related to the synergetic change of source productivity, transport efficiency and accumulation rate over the Antarctic ice sheet, that are all climate dependent (e.g. Petit and Delmonte, 2009).

Arctic ice records originate predominantly from the many Greenland ice sheet drilling sites (e.g. Langway et al., 1985, and reference therein). Hamilton and Langway (1967) interpreted the dust variations in Greenland ice as mainly due to higher aridity in the dust source areas and/or a more vigorous atmospheric circulation in the Northern hemisphere during cold intervals. Based on mineralogical and isotopic $\left({ }^{87} \mathrm{Sr} /{ }^{86} \mathrm{Sr}\right.$ and $\left.{ }^{143} \mathrm{Nd} /{ }^{144} \mathrm{Nd}\right)$ analysis of dust from Greenland ice cores, and comparison with samples from possible Northern hemisphere source areas, those arid source areas have been found to be the deserts of Eastern Asia from the Last Glacial period through the present (Biscaye et al., 1997; Svensson 
et al., 2000; Bory et al., 2002; Lupker et al., 2010). Aeolian sediment transported from these source areas is also considered the source of the extensive loess deposits in the Chinese loess plateau, some of the fine-grained fraction of which has been transported as far as Greenland, especially during loess-depositing, glacial episodes (Biscaye et al., 1997).

The best known dust records from Antarctica came from the Vostok and EPICA (European Project for Ice Coring in Antarctica) ice cores. Vostok provided the first dust record of the last 420,000 years (e.g. Petit et al., 1999) and revealed that the dust input to Antarctica was maximum during glacial periods, lower during stadials and interstadials, and minimum in interglacials. The EPICA-Dome $\mathrm{C}$ ice core provided several high-resolution dust records (Delmonte et al., 2008; Lambert et al., 2008) and to date represents the longest polar ice core record (EPICA-CommunityMembers, 2004; Jouzel et al., 2007), which extends into the Early Pleistocene. Dust content in these sites has been extensively studied for concentration (Petit and Delmonte, 2009) and isotopic $\left({ }^{87} \mathrm{Sr} /{ }^{86} \mathrm{Sr}\right.$ and ${ }^{143} \mathrm{Nd} /{ }^{144} \mathrm{Nd}$ ) composition (e.g. Grousset et al., 1992; Basile et al., 1997; Delmonte et al., 2008, 2010), which was compared with possible source areas from the Southern hemisphere (Revel-Rolland et al., 2006; Gaiero, 2007; Gaiero et al., 2007) in order to gather information on dust provenance. Isotopic studies suggested that Patagonia has been the most important source for dust in the central part of the East Antarctic ice sheet during Pleistocene glacial ages. However the isotopic fingerprint of ice core dust is well documented only for dust deposited during Pleistocene glacials (Basile et al., 1997) and only scarce information exists for interglacials and modern dust (Delmonte et al., 2007; Bory et al., 2010; Gabrielli et al., 2010; Vallelonga et al., 2010).

Iron oxides are magnetic minerals, which are able to carry a remanent magnetization. They are common in nature and constitute typically a small fraction of terrigenous minerals. The most common and chemically stable magnetic minerals are hematite $\left(\gamma \mathrm{Fe}_{2} \mathrm{O}_{3}\right)$, maghemite $\left(\alpha \mathrm{Fe}_{2} \mathrm{O}_{3}\right)$ and magnetite $\left(\mathrm{Fe}_{3} \mathrm{O}_{4}\right)$. They are likely to be found in the aerosol reaching polar regions, which is mostly composed of terrigenous dust originating in desert areas; as a consequence, polar ice is expected to show the characteristic magnetic properties of these minerals that may reflect their provenance and transport history. Investigating the magnetization of ice is thus a method to obtain information about polar ice mineral dust.

The extremely low concentration of magnetic minerals in ice inhibits the possibility to study the natural remanent magnetization. Currently the information obtained from the study of ice cores is limited to the concentration and the nature of the magnetic fraction of aerosol dust. These properties can potentially be used as tracers that may reflect the total dust concentration as well as the availability of iron oxides in the dust source area.

Meteoritic material provides another possible source of magnetic minerals in polar ice. The magnetic minerals are nanometer-sized particles, which are part of the meteoritic smoke that results from the vaporization of micrometeorites as they enter the atmosphere. Because of the strong magnetization of meteorites (e.g. Suavet et al., 2009), the meteoritic smoke can account for a significant fraction of ice magnetization even far from placer deposits and especially during interglacial periods when the deposition of dust in the polar regions is greatly reduced. If the magnetization carried by extraterrestrial material (meteoritic) is distinguished from the terrestrial (dust) fraction, it may provide an estimate of meteoritic accretion (Winckler and Fischer, 2006).

In this paper we review the investigations on the magnetic properties of terrestrial airborne dust in polar regions and their insight on the dust provenance, as well as the information that they provided on meteoritic accretion.

\section{Magnetization of polar ice}

To our knowledge the first published work that described attempts to measure magnetization in polar ice is the study of Funaki and Sakai (1991) who successfully studied the acquisition of natural remanent magnetization in ice samples with a high concentrations of magnetic mineral from a tephra deposit in the Southern Victoria Land, East Antarctica. Sahota et al. (1996) measured Isothermal Remanent Magnetization (IRM) and coercivity of remanence in samples obtained by melting ice and snow from Greenland and Himalayan ice cores through filter paper although samples from Greenland did not give relevant results due to their very low dust concentration. A few years later Funaki (1998) successfully measured natural remanent magnetization and IRM on ice samples from placer deposits (referred to as "dirt" ice) on the Antarctic coast in order to identify micrometeoritic contents. Thanks to the high concentration of magnetic particles in these ice samples, Funaki (1998) was able to measure and stepwise demagnetize the natural remanent magnetization of the highly magnetic "dirt" ice. These ice samples from placer deposits had saturation IRM of about $70-80 \mathrm{~mA} \mathrm{~m} / \mathrm{kg}$ (Funaki, 1998) that was several orders of magnitude larger than the saturation IRM measured by Funaki in the so-called "clean" ice from the Mizuho Station ice core.

Subsequent experiments on ice magnetism (Lanci et al., 2001, 2004) have shown that the acquisition of remanent magnetization in ice samples and its measurements need peculiar precautions in order to obtain consistent and repeatable results. In particular Lanci et al. (2001) noticed that an IRM in ice induced at "freezer" temperature (about $255 \mathrm{~K}$ ) produced erratic results in the intensity and direction of the remanent magnetization. This unexpected behavior was tentatively explained as the effect of the physical reorientation of the magnetic particles in the ice matrix by their local heating due to electromagnetic induction. Whatever the reason of this peculiar behavior, Lanci et al. (2001) found that repeatable results could be obtained by inducing IRM at lower temperatures, which evidently keeps the magnetic particles more solidly frozen in the ice and thereby inhibiting physical rotations. Further experiments have shown that it is possible to perform reliable measurements of IRM at $\sim 255 \mathrm{~K}$ if the magnetization was previously induced at lower temperature. This effect and the need to keep the ice sample frozen limit the kind of rock-magnetic experiments that can be performed on ice samples.

With the above-mentioned limitations, polar ice samples can be given IRMs that can be measured in the laboratory (Lanci et al., 2001). To deal with the extremely low magnetic moment of ice, the samples had to be carefully cleaned before measurements similarly to what is routinely done in geochemical analyses. The cleaning procedure performed in samples of polar ice cores included scraping the external part of the sample with a nonmagnetic knife and multiple baths in ultra-pure water in order to melt, and thus remove, the potentially contaminated external part of the samples. The introduction of extra baths and the use of a class 100 laminar flow hood in Lanci and Kent (2006) and subsequent works have noticeably reduced noise in the remanence measurements relative to earlier results.

The extremely low ice magnetizations also require the verification of the background noise level of the measurement procedure. Lanci et al. (2004) measured artificial ice samples made with ultra-pure water that were treated exactly as natural ice samples and subject to the same cleaning, cooling, magnetization and measurement procedure. Results gave an average mass magnetization of about $3 \mathrm{nA} \mathrm{m} / \mathrm{kg}$ and a repeatability for each samples ranging from $5 \%$ to $15 \%(\sigma)$, which was considered satisfactory given the very low magnetic moments $\left(6-30 \times 10^{-11} \mathrm{~A} \mathrm{~m}^{2}\right)$ of these 
samples. Such a noise level $(\sim 3 \mathrm{nA} \mathrm{m} / \mathrm{kg})$ included analytical errors and possible laboratory contamination that could have been accidentally acquired during handling, and was regarded as adequate for ice measurements. Lower background noise can probably be achieved by performing the whole measurements procedure in a clean room.

Most of the magnetic measurements performed on ice samples consist of stepwise IRM acquisition, which comprise the exposure of the sample to a magnetic field and subsequent measurements of the resulting remanent magnetization after each step. IRM is usually induced in the sample at $77 \mathrm{~K}$ and can be measured keeping the samples at nearly the same temperature (referred here as IRM $_{77 \mathrm{~K}}$ ) or after warming the samples to "freezer" temperature $\left(\mathrm{IRM}_{255 \mathrm{~K}}\right)$. IRM is normally acquired starting from zero-field (i.e., natural magnetization) and progressively increasing the field. Alternatively, the "backfield" IRM method can be used, in which case the sequence of measurements starts with a magnetization at maximum field followed by stepwise increasing fields in the opposite direction (Lanci et al., 2008a, b). This latter method also allows to readily estimate the coercivity of remanence $\left(H_{c r}\right)$, which is defined as the field needed to nullify the backfield IRM and is in practice computed by the intercept of the backfield IRM curve with the zero of the ordinate axis. The shape of the IRM acquisition curve and the field at which saturation is achieved give an indication on the type of magnetic mineral whereas the intensity of IRM is proportional to its concentration. $H_{c r}$ is a convenient parameter to distinguish high- and low-coercivity minerals and was also used to reveal the magnetic mineralogy. The proportion of high- and lowcoercivity minerals was estimated by Lanci et al. (2008a) from $H_{c r}$ using a simple mixing model based on end-members data taken from Robertson and France (1994) (Fig. 1). A computer program to reproduce the $H_{c r}$ mixing curve or to compute it using different end-members is available from the authors upon request.

The consequence of thermal relaxation on fine magnetic particles (e.g. Néel, 1955; Brown, 1963; Bertotti, 1998) was used to investigate the presence of nano-meter-sized magnetic particles and estimate their concentration. In fine particles, the resistance of remanent magnetization against randomizing thermal energy depends on their blocking energy $\left(E_{b}\right)$. For an assemblage of randomly oriented particles $E_{b}$ can be approximated as $E_{b}=\left(v h_{c} J_{s}\right) / 2$, where $v$ is the particle volume, $J_{s}$ their spontaneous magnetization and $h_{c}$ is the coercivity of the assemblage. Under the effect of thermal energy an assemblage of particles relax to an equilibrium state, thus loosing its remanent magnetization, with a time constant $(t)$ that depends exponentially on the ratio of $E_{b}$ to temperature $(T)$ (e.g. Bertotti, 1998). Due to this exponential relationship the approach to thermal equilibrium mostly depends on temperature and $E_{b}$ rather than elapsed time. In addition, within a given magnetic mineral, $h_{c}$ and $J_{s}$ have a relatively restricted range of variability, therefore $E_{b}$ is largely controlled by particle volume. The grains that became unstable with increasing temperature are referred to as superparamagnetic (SP) particles, and their magnetization can be effectively removed by letting the samples warm from $77 \mathrm{~K}$, at which the IRM was induced, to the freezer temperature $(\sim 255 \mathrm{~K})$ over a few hours.

Mineralogy is another factor controlling the thermal stability of the magnetic particles. Chemistry of Fe in the mesosphere can be rather complicated (Helmer et al., 1998) but IRM acquisition curves and analysis of atmospheric dust particles (Rietmeijer, 2001) suggest that the particles are mostly made of maghemite $\left(\gamma \mathrm{Fe}_{2} \mathrm{O}_{3}\right)$ or magnetite $\left(\mathrm{Fe}_{3} \mathrm{O}_{4}\right)$. The dependence of remanent magnetization on grain-size computed for magnetite $\left(h_{c} \sim 150 \mathrm{mT}\right.$ (Tauxe, 2002) and $J_{s}=92 \mathrm{~A} \mathrm{~m} / \mathrm{kg}$ ) using a frequency factor, $f_{0}=1 \times 10^{9}$ (Moskowitz et al., 1997) is schematically shown in Fig. 2. The very small particles at the left side of the diagram cannot carry any

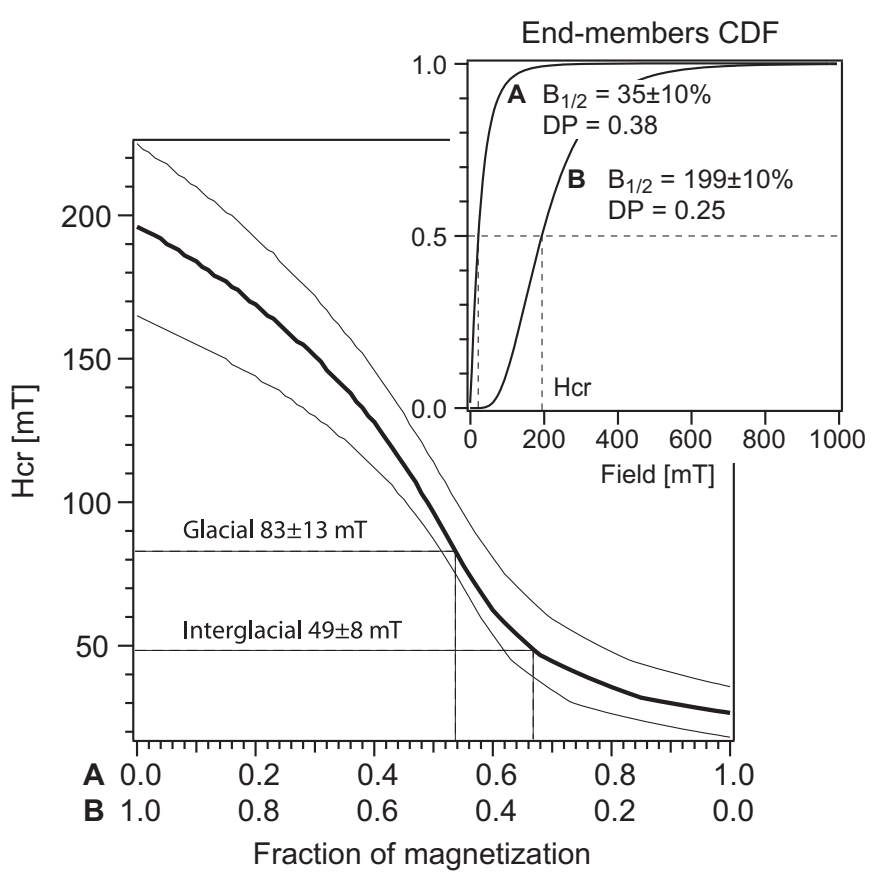

Fig. 1. Mixing model for $H_{c r}$ between the two end-members shown in the inset (A, sample MagB2 and B, sample AH1) and taken from (Robertson and France, 1994), where DP is the dispersion parameter and $B_{1 / 2}$ is the median field. The thin lines show the variability of the model with $a \pm 10 \%$ variation of $B_{1 / 2}$. The average values of glacial and interglacial samples from EPICA-Dome C samples are shown. Redrawn from (Lanci et al., 2008a).

remanent magnetization because the blocking energy is low and their relaxation time is smaller than the time typically elapsed between magnetization acquisition and measurement (here we assume $t \leq 1 \mathrm{~s}$ ). At $77 \mathrm{~K}$ the diameter of a spherical equivalent magnetite particle at which the thermal energy exceed the blocking

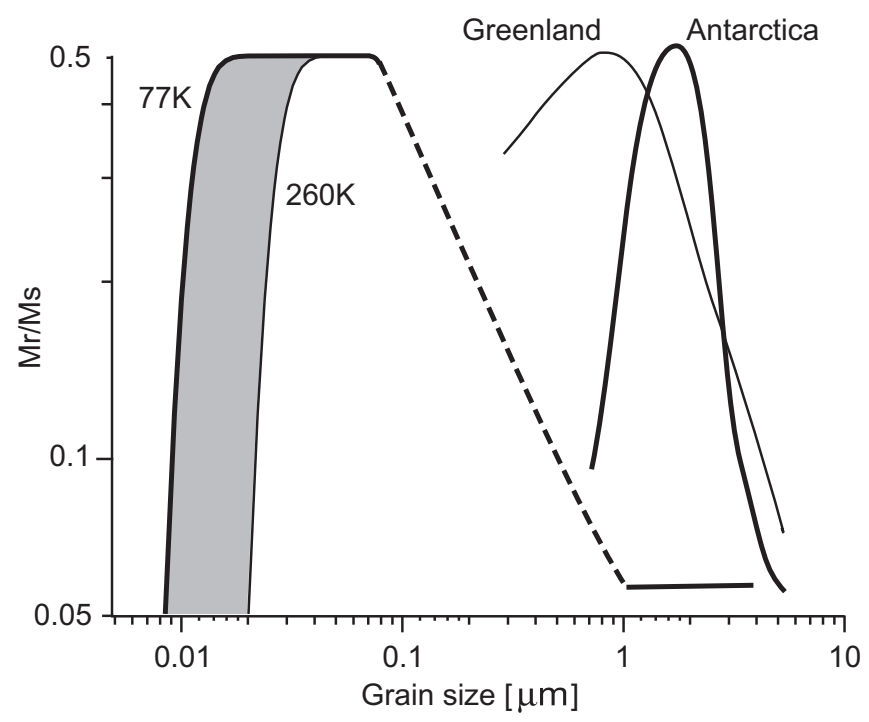

Fig. 2. Schematic representation of the remanent magnetization as function of the particle grain size for magnetite. The most efficient granulometric fraction (single domain, SD) has a narrow range limited on one end by thermal relaxation, which is dependent in temperature, and on the other end by the multi-domain (MD) state; the transition from SD to MD (dashed line) is somewhat uncertain. The gray area represents the granulometric fraction that looses its magnetization by warming from $77 \mathrm{~K}$ to $260 \mathrm{~K}$. The grain-size distribution of the insoluble dust in polar ice is also shown for comparison. 
energy is about $7 \mathrm{~nm}$. The thermal effect will act effectively on larger particles with increasing temperature and at $255 \mathrm{~K}$ the particle diameter for the same kind of SP behavior is about $17 \mathrm{~nm}$. Therefore increasing the temperature from $77 \mathrm{~K}$ to $255 \mathrm{~K}$ causes the remanence of particles between $\sim 7 \mathrm{~nm}-\sim 17 \mathrm{~nm}$ to be lost so that the total magnetization of the samples may be reduced correspondingly if such a grain-size fraction exists in the sample (Fig. 2). Very similar results are obtained for maghemite. Calculations for high-coercivity minerals such as hematite $\left(\mathrm{Fe}_{2} \mathrm{O}_{3}\right)$ or goethite $(\alpha \mathrm{FeOOH})$, which could represent minor magnetic minerals in ice, would result in spherical equivalent diameters ranging from $5 \mathrm{~nm}$ to $30 \mathrm{~nm}$ with a wider range due to their more variable magnetic properties. Here we take the range from $\sim 7 \mathrm{~nm}-\sim 20 \mathrm{~nm}$ as representative of SP particles and we refer to the magnetization measured after warming to $255 \mathrm{~K}$ as $\mathrm{IRM}_{255 \mathrm{~K}}$ (also called Stable Magnetization in previous papers) even if, for practical reasons, the samples were sometimes cooled again at $77 \mathrm{~K}$ in a field-free environment just before measurements. The magnetization carried by the SP particle fraction (IRM $\mathrm{SP}_{\mathrm{SP}}$, was computed as the difference $I_{R M}=I_{S M} 77 \mathrm{~K}-I_{R M} 255$.

\section{Dust concentration and ice magnetization}

The Insoluble Dust Concentration (IDC) in polar ice is routinely measured with a Coulter counter or laser scatter techniques (e.g. Steffensen, 1997; Ruth et al., 2003). The grain-size distribution of the aerosol dust reaching polar regions is usually approximated by a log-normal curve with a modal value of about $1.5 \mu \mathrm{m}$ in Greenland and a larger mode of about $2 \mu \mathrm{m}$ in Antarctica (Steffensen, 1997; Delmonte et al., 2002) with a minor variability between glacial and interglacial ages. Measurements of the lower tail of the grain-size distribution is restricted by the detection limit for the Coulter Multizier II used for IDC measurements at about $0.2-1 \mu \mathrm{m}$, depending on the apparatus settings. The stable remanent magnetization is efficiently carried only by stable SD grains, which in the case of magnetite/maghemite, have a rather narrow grainsize range with diameter smaller than $0.07 \mu \mathrm{m}$ according to the calculations of Winklhofer et al. (1997) and the experimental measurements of Dunlop (1973) (see also Dunlop (1981)). A slightly larger range is suggested by the calculation of Newell and Merrill (2000a) and Newell and Merrill (2000b) who suggest an upper limit for stable SD particles of $0.1 \mu \mathrm{m}$ and a rather sharp transition between SD and multi-domain grains. In any case the SD maximum size falls definitively below the minimum detection limit of the Coulter counter (Fig. 2). One important question is if the measurements of IDC are really informative of the amount of fine magnetic particles in the ice since their dimension are very different from that of the insoluble dust. To answer this question it should be considered that iron oxides have a much larger density than average silicates i.e., $5200 \mathrm{~kg} / \mathrm{m}^{3}$ for magnetite compared with the average silicate value of $2500 \mathrm{~kg} / \mathrm{m}^{3}$ (e.g. Steffensen, 1997) and their sedimentation speed or wind-shear effect (aerodynamic diameter) is equivalent to those of larger silicate particles. Moreover, magnetic particles are often electrostatically attached to larger clay particles, and the airborne dust has a relatively well-shaped log-normal distribution allowing to extrapolate concentration of the finest grains. However, more definitive answers come from the results that show a linear correlation between IDC and IRMs.

\subsection{Results from North GRIP ice core}

Results from the North GRIP ice core in central Greenland (75.9N, 42.3W, Fig. 3a) are the outcome from a set of 50 ice samples representing 5 different climatic intervals including ice from the Pre-Boreal to the Last Glacial Maximum as described in Lanci et al. (2004) and Lanci and Kent (2006). Fig. 4 shows the depth of these intervals and their position relative to the dust and $\delta^{18} \mathrm{O}$ records. The IDC was measured with Coulter Multisizer II on samples taken from the same core interval. The depth and the volumes of the IRM and Coulter counter specimens do not correspond exactly and for this reason we compare the average values at each of the five depth intervals.

Another set of 30 samples from North GRIP was taken the onset of Dansgaard/Oeschger event \#5 (Fig. 4) (Lanci et al., 2004; Lanci and Kent, 2006). The IDC in these samples was measured by Ruth et al. (2003) using a laser microparticle detector and normalized to Coulter Multisizer measurements as described in Lanci et al. (2004). Unfortunately one single laser detector measurement represents the average of the entire, $50 \mathrm{~cm}$ long, interval thus an estimate of the ICD variability is not available.

The magnetization of ice is expected to be proportional to the concentration of magnetic minerals and to the IDC under the simple assumption of a constant magnetic mineralogy of dust. Measurements on the North GRIP ice core have shown that correlation between ice magnetization and dust concentration is indeed
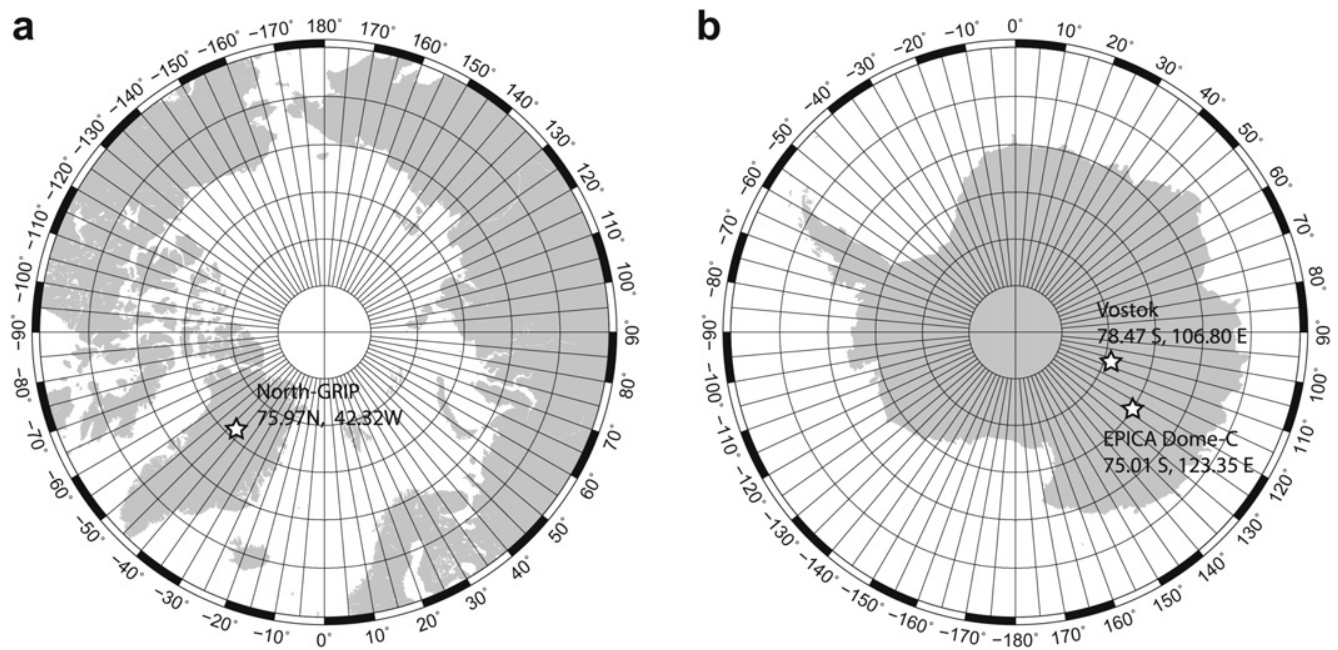

Fig. 3. Location maps of ice cores studied for magnetic properties. 

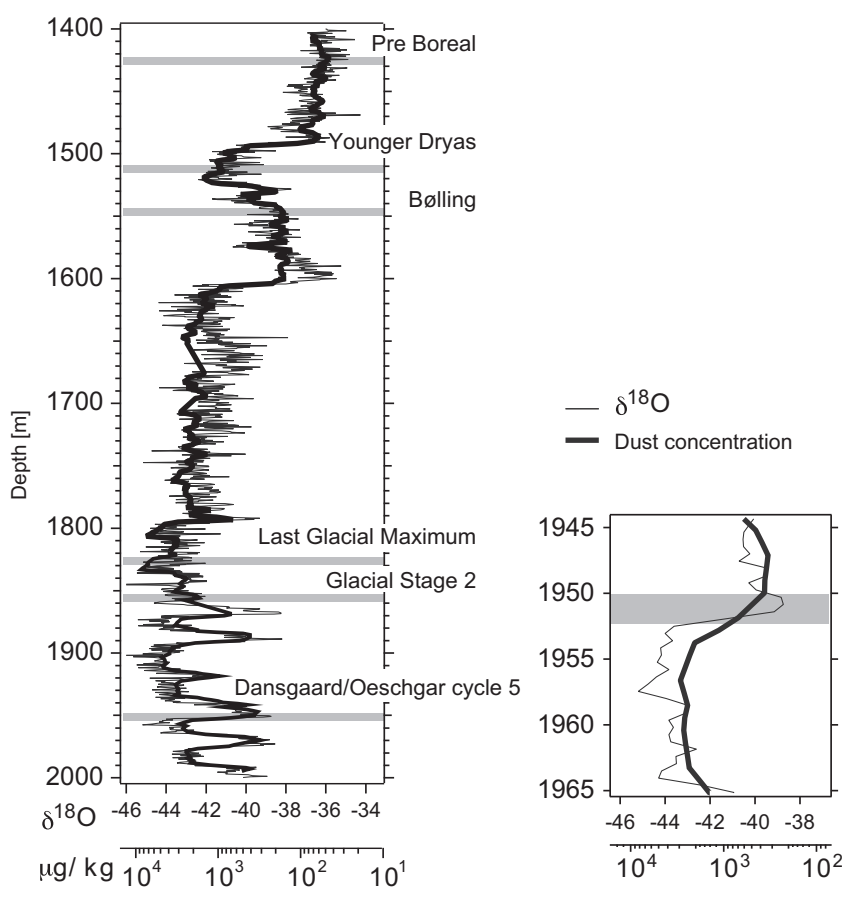

Fig. 4. Sampled intervals compared with oxygen isotope $\left(\delta^{18} \mathrm{O}\right)$ and IDC profiles from the North GRIP ice core. The inset shows the detailed position of the samples taken from the Dansgaard/Oeschger cycle \#5 transition.

straightforward when the $\mathrm{IRM}_{255 \mathrm{~K}}$ is considered. The linear regression of IDC and $\mathrm{IRM}_{255 \mathrm{~K}}$ is shown in Fig. 5. Each point represents the average value of one climate interval with the standard deviations $( \pm \sigma)$ shown as error bars. Therefore $\sigma$ represents the measurement error plus the natural variability of IRM and

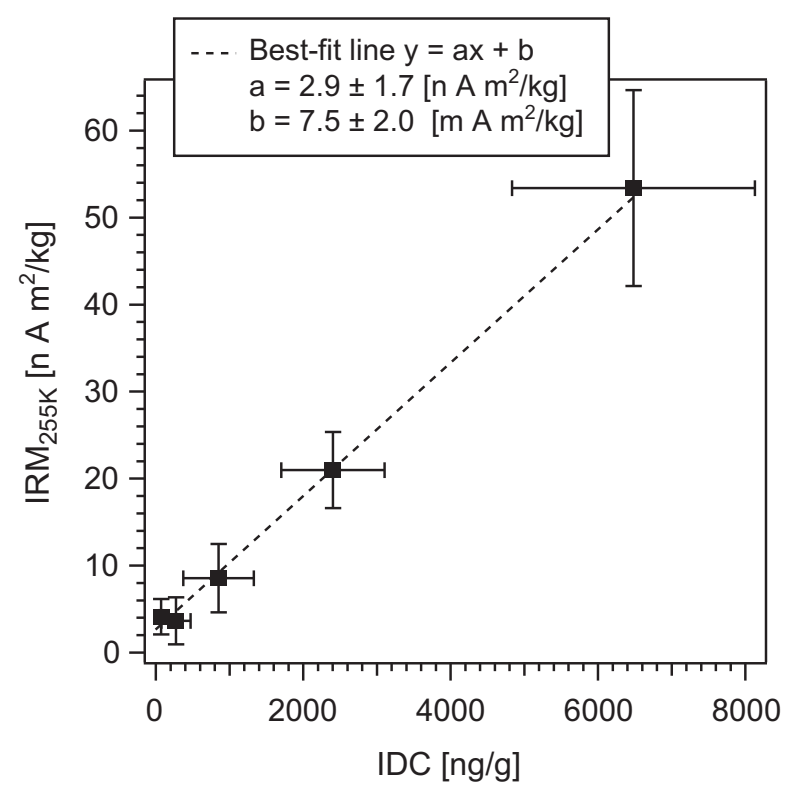

Fig. 5. Linear correlation between $I_{R M_{255 K}}$ and IDC in North GRIP ice core. Each point is the average of several samples from the same climatic stage and error bars are the standard deviation $( \pm 1 \sigma)$, denoting the natural variability of these variable and not just the analytical errors. The slope $(b)$ of the regression line represents the average magnetization of the dust at $255 \mathrm{~K}$ (dust $\mathrm{IRM}_{255 \mathrm{~K}}$ ) and the good line fit suggests that magnetization is constant within glacial and interglacial stages. The intercept $a$ is indistinguishable from background laboratory noise, which was estimated to be $\sim 3 \mathrm{n} \mathrm{A} \mathrm{m}^{2} / \mathrm{kg}$.
IDC at the different climatic stages. It is noteworthy that this variability is similar for both magnetization and dust contents.

The linear regression in Fig. 5, computed considering errors in both coordinates, is highly significant $(p>0.99)$; it has a $y$-axis intercept indistinguishable from the laboratory noise level of $\sim 3 \mathrm{nA} \mathrm{m} \mathrm{m}^{2} / \mathrm{kg}$, and a slope of the regression line ( $b=7.5 \pm 2.0 \mathrm{~mA} \mathrm{~m} / \mathrm{kg}$ ) that represents the optimal mean value of the insoluble dust IRM $_{255 \mathrm{~K}}$. Furthermore, the excellent linear correlation suggests that there are no significant changes of the dust magnetization, hence possible dust source areas from glacial to interglacial periods.

The absence of major variations of magnetic mineralogy between glacial and interglacial samples is confirmed by the

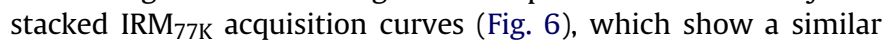
shape for glacial and interglacial samples and substantiate the lack of significant changes in dust provenance during the last glacial to interglacial transition. This finding is in good agreement with geochemical analyses on wind-borne dust that have established an Eastern Asia origin for the aerosol dust deposited in Greenland during both glacial and interglacial periods (Biscaye et al., 1997; Svensson, 1998; Svensson et al., 2000) with only minor seasonal changes observed in recent snow (Bory et al., 2002, 2003). The IRM $_{77 \mathrm{~K}}$ acquisition curve of Greenland ice is also virtually identical to that of pristine (i.e., unweathered) Chinese loess (Fig. 6), which shares the same dust source area.

Concentration of magnetic minerals in Chinese loess, as revealed by IRM, is also similar to that of aerosol dust in Greenland ice. Data from loess horizons L1 to L14 from the central Chinese loess plateau reported from Deng et al. (2004) have an average saturation IRM at room temperature of $5.7 \pm 1.2 \mathrm{~mA} \mathrm{~m} / \mathrm{kg}$, which is similar to the value of $4.5 \mathrm{~mA} \mathrm{~m} / \mathrm{kg}$ measured in loess sample

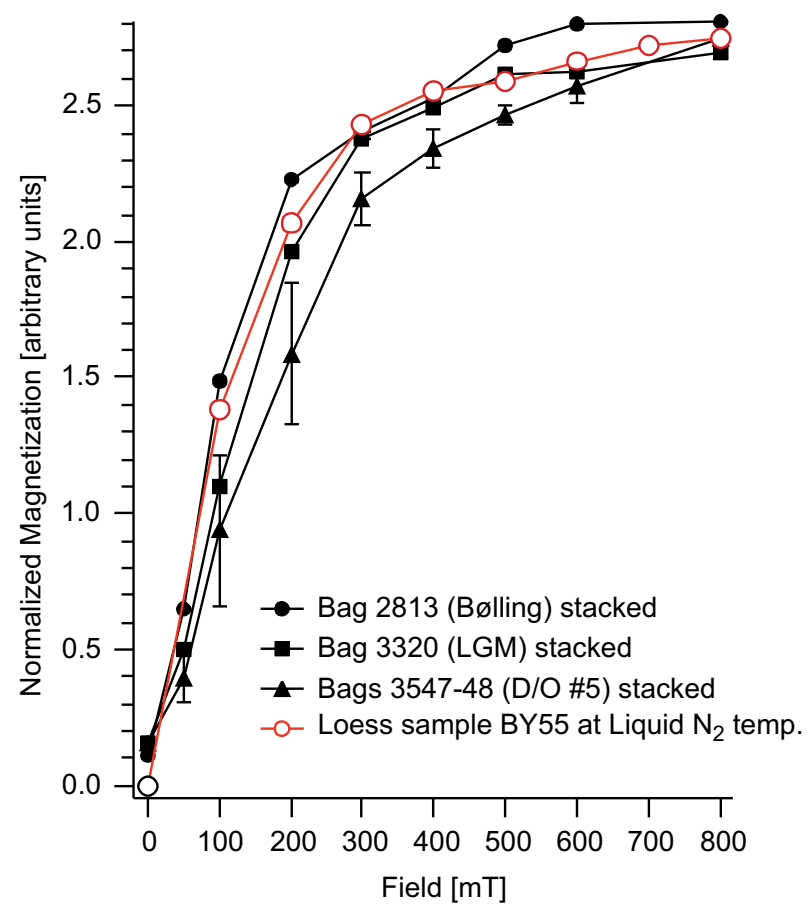

Fig. 6. IRM acquisition curves for North GRIP ice core samples. Each curve represent the stack of several samples from the same climatic interval normalized to unit variance. Error bars of samples from bags 3547-48 (Dansgaard/Oeschger \#5 transition) represent the standard deviation $( \pm \sigma) ; \sigma$ in samples from Bølling and Last Glacial Maximum is smaller than symbol size. IRM 77K acquisition of loess sample BY55 is shown for comparison. The IRM $\mathrm{R}_{300 \mathrm{~K}}$ intensity (at $800 \mathrm{mT}$ ) of loess sample BY55 is comparable to that of Greenland ice dust $\left(7.5 \pm 2 \mathrm{~m} \mathrm{~A} \mathrm{~m}^{2} / \mathrm{kg}\right)$ as they share the same source area (the Gobi Desert). 
BY55. Both values are compatible with the dust IRM $_{255 \mathrm{~K}}$ $\left(7.5 \pm 2.0 \mathrm{~mA} \mathrm{~m}{ }^{2} / \mathrm{kg}\right)$ measured in Greenland ice.

Different magnetic properties were found in ice samples taken at the Dansgaard/Oeschger \#5 transition. These samples do not fit the linear trend of the other North GRIP samples in the IRM $_{255 \mathrm{~K}}$ versus IDC diagram (Lanci et al., 2004) and their average dust IRM $_{255 \mathrm{~K}}$ at $800 \mathrm{mT}$ has a lower value of $\sim 4.4 \pm 2.0 \mathrm{~mA} \mathrm{~m} / 2 / \mathrm{kg}$ compared with the other North GRIP samples. Moreover, Dansgaard/Oeschger \#5 samples show a different IRM acquisition stacked curve (Fig. 6) with a larger contribution of high-coercivity minerals. This suggests that the magnetic mineralogy of insoluble dust changed during the onset of the Dansgaard/Oeschger \#5 event, which is tentatively explained as a different dust provenance and could be indicative of different deflation areas, atypical atmospheric transport or both. Given these incomplete results, the peculiar magnetic properties of the aerosol dust during Dansgaard/Oeschger climatic events definitively deserve further investigations.

\subsection{Results from Vostok ice core}

One of the two sets of samples from Antarctica came from the Vostok ice core $\left(78.47^{\circ} \mathrm{S}, 106.8^{\circ} \mathrm{E}\right.$, Fig. 3b). Samples from the Vostok ice core span in age from the current interglacial (Holocene) to the last glacial period and are clustered in 10 groups of adjacent

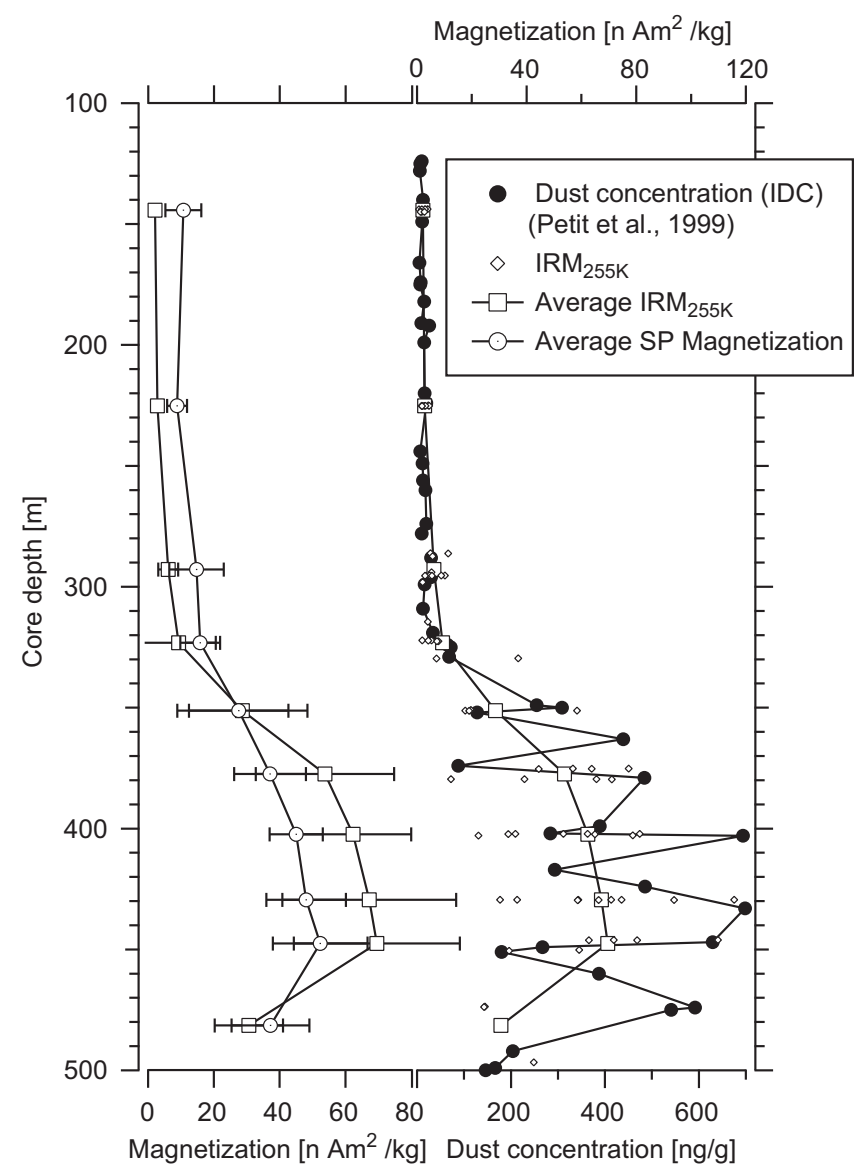

Fig. 7. Summary of IRM measurements on samples from the Vostok ice core compared with IDC data from Petit et al. (1999). The $\mathrm{IRM}_{255 \mathrm{~K}}$ averaged within each group of samples follows well the increase of IDC during the Last Glacial period and has a similar variability even though the insoluble dust measurements came from different samples. Averaged SP magnetization follows the $\mathrm{IRM}_{255 \mathrm{~K}}$ trend with a large background in the Holocene samples which was interpreted as the result of Oeschger fallout (Oeschger smoke). samples (for a total of 72 samples) as shown in Fig. 7 and described in Lanci et al. (2007).

The IRM ${ }_{77 \mathrm{~K}}$ acquisition curves, which were measured in most of the Vostok ice core samples, exhibit a rather large variability even within adjacent samples. Averaged (stacked) IRM I7K $_{7}$ acquisition curves that capture the mean magnetic properties of each group of samples are shown in Fig. 8. The variability in the shape of IRM ${ }_{77 \mathrm{~K}}$ curves, shown by the error bars $( \pm 1 \sigma)$, suggests the presence of a heterogeneous flux of high- and low-coercivity magnetic particles that varied with high time-frequency perhaps due to seasonal or inter-annual variations. However, no significant differences were observed when stacked curves from the glacial and interglacial stages are compared. All stacked curves have a similar highcoercivity component that does not saturate at the maximum field of 1.6 T, which is indicative of the presence of hematite.

Despite the variability of the magnetic mineralogy the ice $\mathrm{IRM}_{255 \mathrm{~K}}$ mimics fairly well the IDC from Petit et al. (1999). The comparison of IRM and IDC downcore variations (Fig. 7) shows that not only the increase of IRM from interglacial to glacial stages is proportionally similar to that of IDC, but also that the overall variability of these parameters are comparable, even though they were measured in different samples. A precise correlation between ice IRM $_{255 K}$ and IDC is shown in Fig. 9 where the IRM $_{255 K}$ and the estimated IDC in equivalent core depth intervals are averaged in 10 groups of adjacent samples. Error bars represent the $\mathrm{IRM}_{255 \mathrm{~K}}$ standard deviation $( \pm 1 \sigma)$, which was not computed for IDC because of the sparsity of data. IDC and IRM $_{255 \mathrm{~K}}$ show a statistically significant linear correlation; the offset $a$ of the best-fit line is indistinguishable from zero, and the slope $b$ represents the best estimate of the average $I_{R M} M_{255 K}$ of insoluble dust in the Vostok ice. This corroborates the finding in North GRIP and confirms that $I_{R M} M_{255}$ is linearly dependent on IDC. The different values of average dust $\mathrm{IRM}_{255 \mathrm{~K}}$ (the slope $b$ of the best-fit line) reflect the different dust

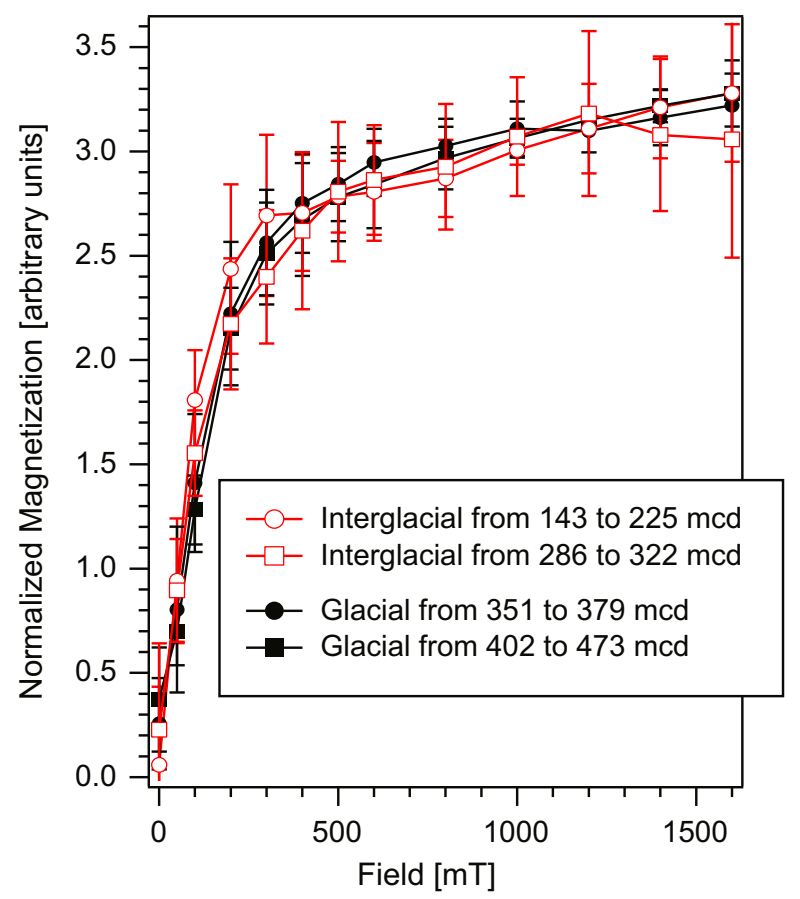

Fig. 8. IRM acquisition curves from Vostok ice core samples stacked by climatic stages. Error bars represent the standard deviation $( \pm \sigma)$. Despite the relatively large variability, there are no noticeable differences between glacial and interglacial ice, suggesting that the magnetic minerals in the insoluble dust reaching the Vostok site are not influenced by climate. 


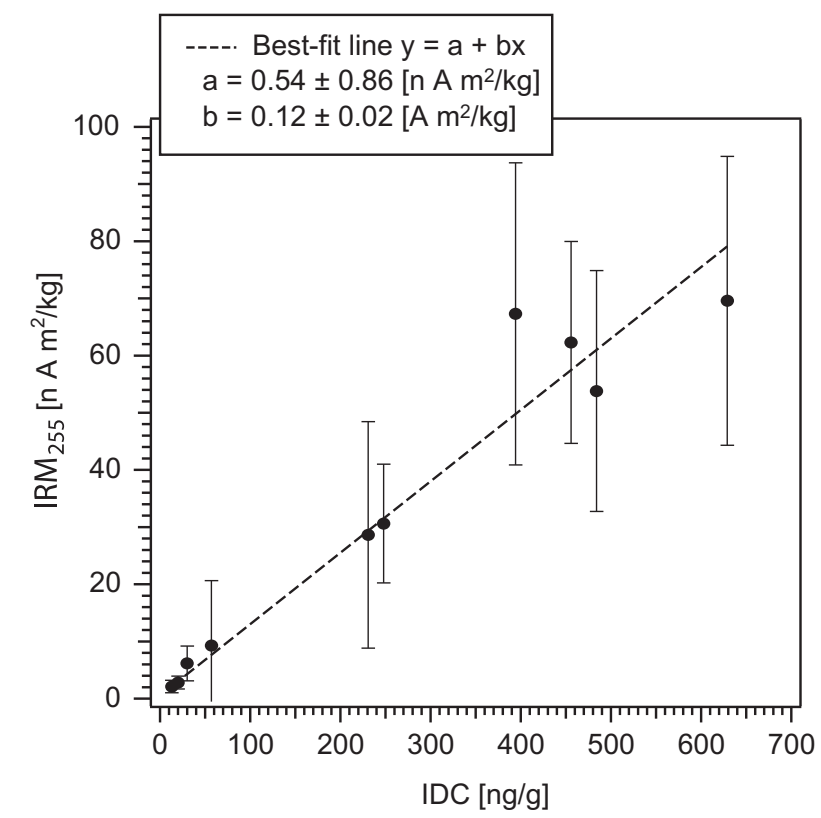

Fig. 9. IDC versus $I_{R M} M_{255 K}$ for the Vostok ice core. $I M_{255 K}$ is averaged by samples groups and the variability is shown as standard variation $\pm 1 \sigma$. IDC is estimated from Petit et al. (1999) for equivalent core depths; data are too sparse to compute the errors bars. The intercept $a$ is indistinguishable from zero. The $b$ coefficient represents the average dust $\mathrm{IRM}_{255 \mathrm{~K}}$.

composition and mineralogy in the opposite hemispheres. In both cores the saturation $\mathrm{IRM}_{255 \mathrm{~K}}$ give a measurement proportional to the dust concentration while the independent values of IDC, when available, allows the calculation of dust IRM $_{255 K}$ which is an intrinsic property of the aerosol dust.

\subsection{Results from EPICA-Dome C ice core}

A total of 41 ice samples from EPICA-Dome C (Lanci et al., 2008a, b) drilled in Antarctica ( $75.1^{\circ} \mathrm{S}, 123.3^{\circ} \mathrm{E}$, Fig. 3b) were selected uniformly along an interval spanning 2 glacial and interglacial cycles from Holocene to marine isotope stage (MIS) 6 (Fig. 10).

The magnetic properties of the aerosol dust in EPICA-Dome $\mathrm{C}$ ice have been characterized mainly by IRM intensity and $H_{c r}$. In this ice core the magnetic measurements showed a distinct difference between glacial and interglacial dust mineralogy, as revealed by the $\mathrm{IRM}_{77 \mathrm{~K}}$ acquisition curves of representative samples (Fig. 11). Ice samples from interglacial stages saturate at a field of about $0.3 \mathrm{~T}$, which is interpreted as indicative of low-coercivity minerals, while glacial samples do not reach saturation in the maximum field of $1.5 \mathrm{~T}$, which indicates the presence of a large amount of high-coercivity mineral. The different magnetic mineralogy is also shown by distinct values of $H_{c r}$ from which the fraction of IRM carried by low-coercivity mineral (magnetite) can be estimated using the mixing model of Lanci et al. (2008a) (Fig. 1). However, no significant differences in magnetic properties have been observed in interglacial samples from the Holocene and MIS 5.5. Similarly, glacial samples from the Last Glacial Maximum and MIS 6 have virtually identical magnetic properties. Because of the variability of magnetic mineralogy in samples from different climatic stages, and since different magnetic minerals have different spontaneous magnetizations, a linear correlation between ICD and IRM $_{255 K}$ cannot be expected for EPICA-Dome C samples. However, an excellent correlation can be obtained if a subset of samples with uniform mineralogy is selected (Fig. 12). This was obtained by choosing samples between a narrow coercivity range $\left(40.3 \leq H_{c r} \leq 51.6 \mathrm{mT}\right)$.

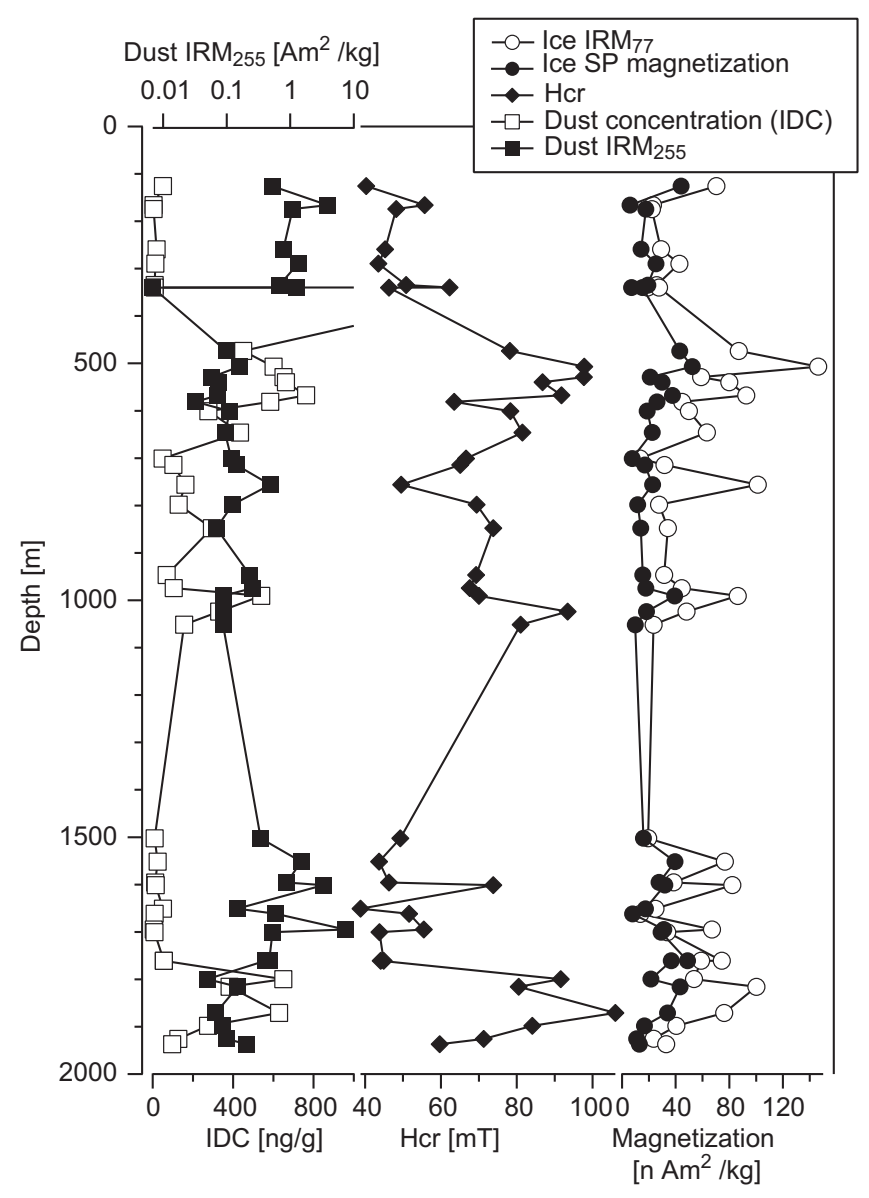

Fig. 10. Summary of magnetic measurements from EPICA-Dome $C$ ice core compared with IDC. Sample at $340.2 \mathrm{~m}$ depth has an anomalously high dust concentration that falls out of scale, perhaps due to a volcanic ashes layer. Ice magnetization in EPICA samples do not show the general correlation with dust observed in North GRIP and Vostok. Moreover, the variability of $H_{c r}$ indicates a change in magnetic mineralogy from glacial to interglacial samples suggesting that magnetic mineralogy may be controlled by and thus indicative of climatic factors. The dust $\mathrm{IRM}_{255 \mathrm{~K}}$ is computed dividing the $\mathrm{IRM}_{255 \mathrm{~K}}$ of the whole ice sample by its IDC and is indicative of concentration of magnetic minerals in the insoluble dust.

Further differences from glacial and interglacial stages are found in the dust IRM $255 \mathrm{~K}$, which is computed by dividing the ice $\mathrm{IRM}_{255 \mathrm{~K}}$ by IDC. The dust IRM $_{255 \mathrm{~K}}$ is carried by the fraction of magnetic grains larger than $\sim 20 \mathrm{~nm}$, therefore it is not affected by the background of Oeschger smoke fallout (Lanci et al., 2007) and is indicative of the concentration of magnetic minerals in the insoluble dust. The large average dust IRM $_{255 K}$ of the set of (mostly) interglacial samples is shown by the regression-line slope $b=0.45 \mathrm{~A} \mathrm{~m}^{2} / \mathrm{kg}$ (Fig. 12). Interglacial dust in EPICA-Dome C ice core was found to be up to 10 fold more magnetic than glacial dust even disregarding some outliers of interglacial period (samples EDC2712-07, EDC3082-07 and EDC302-07) with an extremely high dust magnetization.

These two magnetic properties (dust IRM $255 \mathrm{~K}$ and $H_{c r}$ ) of EPICADome $C$ are combined in Fig. 13, which shows the different clustering of glacial and interglacial samples as well as the few outliers. Such a marked difference in magnetic properties of interglacial aerosol dust is suggestive of a different provenance and/or source. The high dust magnetization of the outlier samples (EDC2712-07, EDC3082-07 and EDC302-07) might need further explanation, such as concentration of volcanic ashes or the occasional occurrence of micrometeorites, which can have very large magnetization (e.g. Suavet et al., 2009). 


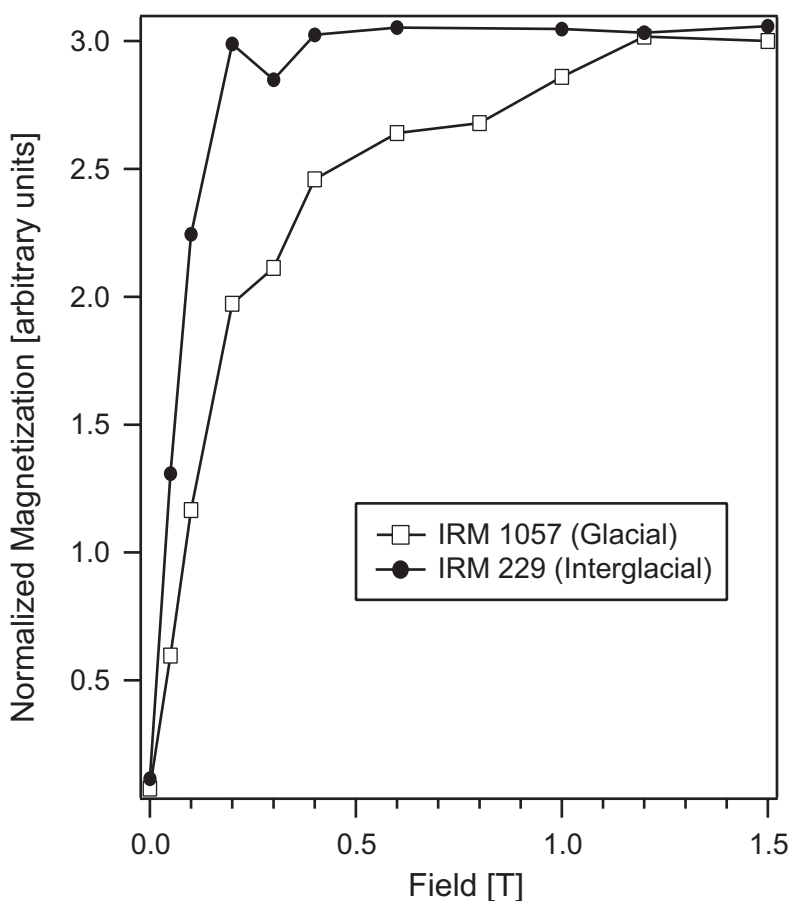

Fig. 11. Typical IRM acquisition curves from EPICA-Dome $C$ samples that show distinctly different magnetic mineralogies in glacial and interglacial samples. The different mineralogies can be used to discriminate different provenance of the dust during the different climate stages.

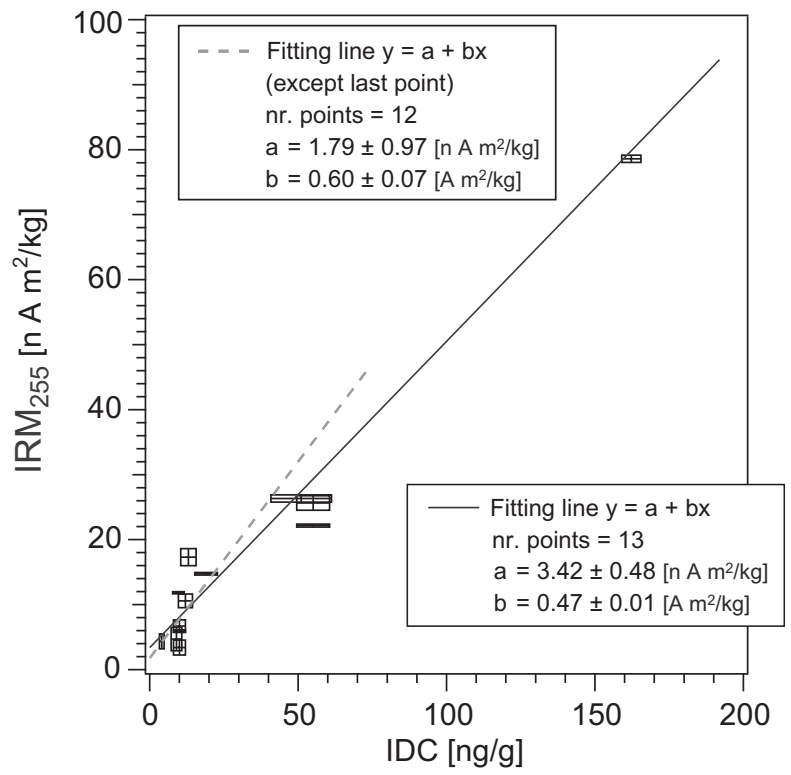

Fig. 12. IDC versus $I_{R M} M_{255}$ for the EPICA-Dome $C$ ice core. The samples were selected based on similar low values of $H_{c r}\left(40.3 \leq H_{c r} \leq 51.6 \mathrm{mT}\right)$, which characterize mostly interglacial samples and reflect a constant magnetic mineralogy. The slope $b$ of the best-fit line represents the average magnetization at $255 \mathrm{~K}\left(\mathrm{IRM}_{255 \mathrm{~K}}\right)$ of EPICA-Dome $\mathrm{C}$ interglacial dust (not the magnetization of the ice). Best-fit line was also computed excluding the top-right sample (dashed line) to test robustness of results. In both cases the intercept $a$ is indistinguishable from background laboratory noise estimated as $\sim 3 \mathrm{n} \mathrm{A} \mathrm{m}^{2} / \mathrm{kg}$. The $b$ coefficient represents the average dust $\mathrm{IRM}_{255 \mathrm{~K}}$ which is much higher than at Vostok. Points are single sample measurements and the box dimensions represent the analytical errors estimated by repeated measurements (note that this is different from the error bars in Figs. 5 and 9).

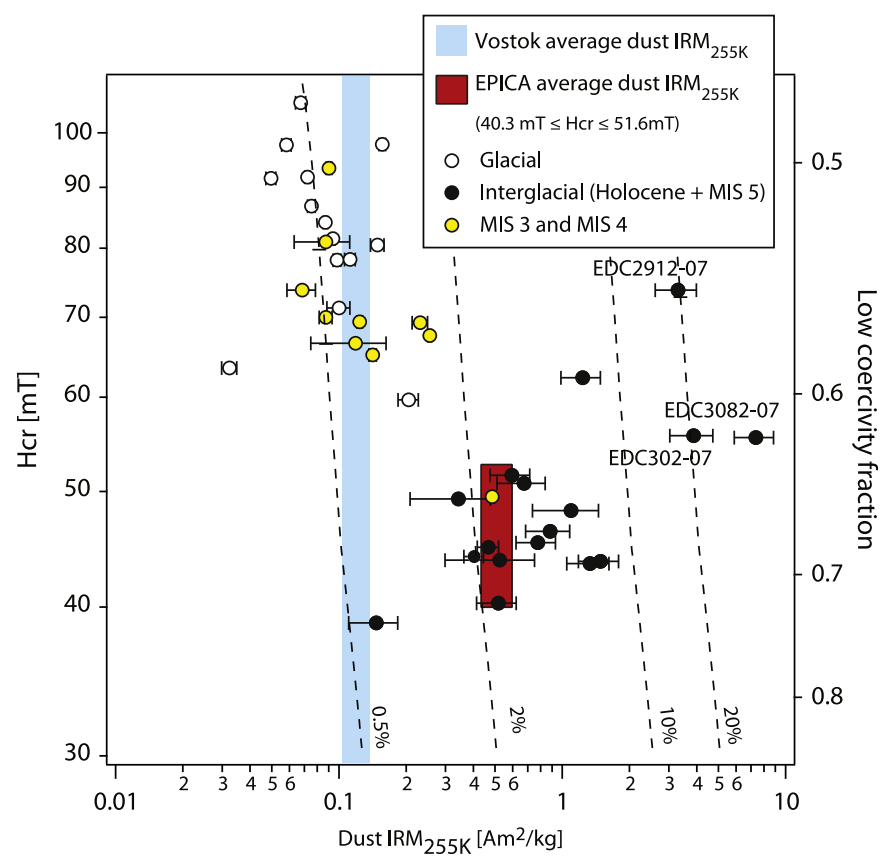

Fig. 13. Magnetic properties of insoluble dust from the EPICA-Dome $C$ ice core. The analytical error of the dust IRM $255 \mathrm{~K}$ is estimated as $\sqrt{\left(\sigma_{\mathrm{IRM}} 255 \mathrm{~K} / \mathrm{IRM}_{255 \mathrm{~K}}\right)^{2}+\left(\sigma_{\mathrm{IDC}} / \mathrm{IDC}\right)^{2}}$ (Lanci et al., 2008a). The dust IRM 255K of EPICA interglacial samples is indistinguishable from the average magnetization of Vostok (glacial + interglacial) samples shown by the long vertical band centered on the mean value with a $2 \sigma$ width whereas EPICA interglacial samples are well distinct (short vertical band). The fraction of IRM carried by a low-coercivity mineral corresponding to the $H_{c r}$, is estimated based on mixing model of Lanci et al. (2008a) depicted in Fig. 1. Dashed lines are the estimated concentration of iron oxides in the aerosol dust computed assuming a remanent magnetization $M_{r}=30 \mathrm{~A} \mathrm{~m}^{2} / \mathrm{kg}$ for the low-coercivity fraction and $M_{r}=0.2 \mathrm{~A} \mathrm{~m}^{2} / \mathrm{kg}$ for the high-coercivity fraction. Samples EDC2712-07, EDC3082-07 and EDC302-07 have an anomalous high magnetization and thus Fe-oxides concentration that could be indicative of volcanic or meteoric dust (note the logarithmic scale).

\subsection{Dust provenance in Antarctica}

The average value of dust IRM $_{255 \mathrm{~K}}$ of EPICA-Dome $\mathrm{C}$ glacial samples is practically indistinguishable from that of Vostok samples, in this case from both glacial and interglacial stages. However EPICA-Dome $C$ interglacial samples display a much larger dust magnetization and coercivity (Table 1, Fig. 13). The magnetic properties of ice from EPICA-Dome $C$ and Vostok show a similar picture (Fig. 14). From a rock-magnetic point of view the EPICADome $\mathrm{C}$ ice during glacial times is completely similar to the Vostok ice, but EPICA-Dome $C$ interglacial ice is very different from Vostok interglacial ice. Interglacial ice from EPICA-Dome $C$ is in general more magnetic and has occasionally a very large magnetization, comparable with glacial ice, which is not due to an increase of dust concentration but rather to the occurrence of highly magnetic aerosol dust that is not found in Vostok.

The different magnetic mineral concentrations observed in the aerosol dust and the different magnetic mineralogy provide evidence that dust load has a geographic variability and that Vostok and EPICA-Dome $\mathrm{C}$ mineral dust sources were different during

Table 1

Summary of magnetic properties of insoluble aerosol dust.

\begin{tabular}{ll}
\hline & Dust IRM $_{255 \mathrm{~K}}\left(\mathrm{~A} \mathrm{~m}^{2} / \mathrm{kg}\right)$ \\
\hline North GRIP & $7.5 \pm 2 \times 10^{-3}$ \\
Vostok & $0.12 \pm 0.02$ \\
EPICA $\left(40.3 \leq H_{c r} \leq 51.6 \mathrm{mT}\right)$ & 0.45 \\
\hline
\end{tabular}




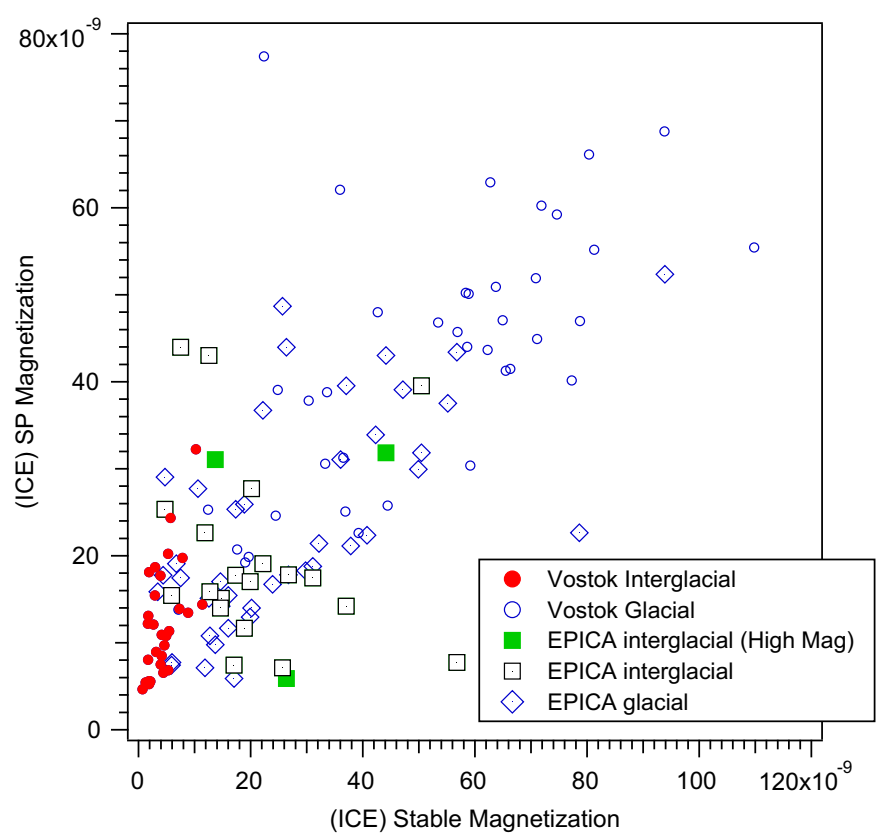

Fig. 14. Comparison of magnetic properties of Vostok and EPICA-Dome C ice. EPICA interglacial samples are Holocene and MIS 5 in age, glacial samples include MIS 3 and MIS 4. Glacial samples from EPICA are indistinguishable from Vostok samples based on ice magnetization but a large difference is observed in interglacial samples. Samples with anomalously high dust magnetization (EDC2712-07, EDC3082-07 and EDC30207) are marked with closed squares.

interglacial stages. These observations indicates the presence of a local source of iron-rich dust particles that supplied Dome C during interglacial stages. The very high magnetization of EPICA-Dome $C$ interglacial samples is probably derived from volcanic rocks in the vicinity as supported by $\mathrm{Pb}$ isotopes data indicating a local volcanic dust contribution to Dome C (Vallelonga et al., 2010). A local volcanic contribution is also consistent with the higher fallout of super-chondritic siderophilic elements on Dome $C$ compared with Vostok (Gabrielli et al., 2006) during the Holocene.

\section{Meteoric smoke and superparamagnetic particles in polar ice}

Polar ice contains a significant amount of SP particles as shown by the difference between $I R M_{77 \mathrm{~K}}$ and $I R M_{255 \mathrm{~K}}$. Moreover, the abundance of these ultra-fine magnetic grains is not proportional to the IDC as they became the predominant magnetic signal during interglacial periods. The increased concentration of SP particles during interglacials is unlikely to be a consequence of a change in the grain-size distribution of airborne dust from glacial to interglacial periods. This would have required a dramatic change that would have affected the entire range of grain distribution, while the observed differences are small in Greenland (Steffensen, 1997) and negligible in Antarctica (Delmonte et al., 2002).

We provide indirect evidence that part of the SP particles in ice is constituted by meteoric particles of nanometric size and propose a simple criterion to discern between terrestrial and meteoric SP contributions.

Most of the meteoric material reaching the Earth is constituted by micrometeorites with a diameter ranging from a few $\mu \mathrm{m}$ to $2 \mathrm{~mm}$ (e.g. Love and Brownlee, 1993); however, the large majority of these particles are likely to vaporize during atmospheric entry at high altitude $(\sim 100 \mathrm{~km})$ and condensate in nanometric-sized particles called meteoric smoke. Even though meteoric smoke has never been observed directly its existence is suggested by theoretical considerations (Hunten et al., 1980; Love and Brownlee, 1991) and indirect measurements (Gabrielli et al., 2004). Moreover, its presence would offer an elegant explanation for the large discrepancy between Earth accretion estimates measured from micrometeorite flux outside the atmosphere by the LDEF experiment (Love and Brownlee, 1993) and the many estimates from micrometeorite counting in ice cores and other terrestrial sedimentary archives (e.g. Taylor et al., 1998), which are often one order of magnitude smaller.

Polar ice represents an ideal place to study meteoric smoke because no alteration or in-situ production of magnetic particles is likely to happen and the magnetic methods provide an interesting method to access its concentration. Extraterrestrial material is rich in iron ( $\sim 20 \%$ on average), in the form of metallic-Fe, Fe-sulphides, olivine and pyroxene. These primary iron phases are subjected to high-temperature oxidation into magnetite $\left(\mathrm{Fe}_{3} \mathrm{O}_{4}\right)$ during the vaporization and melting following atmospheric entry (e.g. Love and Brownlee, 1991; Genge and Grady, 1998; Toppani et al., 2001; Genge et al., 2008) and the resulting meteoritic material is highly magnetic as shown by Suavet et al. (2008, 2009). Because of their dimensions, these nanometric-sized magnetite particles that may constitute the meteoric smoke are expected to be superparamagnetic at temperatures of about $255 \mathrm{~K}$, but they can carry a remanent magnetization if cooled down below their blocking temperature. Furthermore, the volume dependence of the blocking temperature may provide a method to estimate the sizes of these magnetic particles. The span of temperature used in this study, $77 \mathrm{~K}$ (liquid Nitrogen) to $255 \mathrm{~K}$ (freezer) restricts the equivalent spherical diameter of the SP particles to the range of 7-17 $\mathrm{nm}$ for the most likely maghemite $\left(\gamma \mathrm{Fe}_{2} \mathrm{O}_{3}\right)$ or magnetite $\left(\mathrm{Fe}_{3} \mathrm{O}_{4}\right)$ composition or about 5-30 nm for hematite $\left(\alpha \mathrm{Fe}_{2} \mathrm{O}_{3}\right)$ (Lanci and Kent, 2006).

One difficulty in estimating the smoke concentration arises from the fact that SP particles can be produced in a variety of environments and can be common in terrestrial material. The SP particles measured in ice, therefore, are expected to contain a mixture of extraterrestrial (smoke) and terrestrial material, which must be distinguished. We attain this by assuming that terrestrial SP particles are not produced in-situ and are carried to polar regions together with airborne dust. Accordingly, their contribution should correlate linearly with IDC (similar to what is observed with $\mathrm{IRM}_{255 \mathrm{~K}}$ ) and no terrestrial SP contribution to the ice magnetization will occur for zero dust concentration. Extrapolating the regression line between IDC and IRM $\mathrm{SP}_{\mathrm{SP}}$ to the intercept corresponding to zero IDC will, thus, provide an estimate of extraterrestrial SP magnetization of ice (Fig. 15). This method and the equivalent one, which uses the regression between IRM $\mathrm{MP}_{\mathrm{SP}}$ and $\mathrm{IRM}_{255 \mathrm{~K}}$, were used by Lanci and Kent (2006) and Lanci et al. (2007) who reported an isothermal magnetization of ice, due to meteoric smoke ( IRM $_{\text {smoke }}$ ) for Greenland (North GRIP ice core) of $11.0 \times 10^{-9} \mathrm{~A} \mathrm{~m}^{2} / \mathrm{kg}$ and $10.9 \times 10^{-9} \mathrm{~A} \mathrm{~m}^{2} / \mathrm{kg}$ for Antarctica (Vostok ice core) (Fig. 15). In practical terms no difference has been found computing IRM $_{\text {smoke }}$ from IRM ${ }_{255 K}$ or from IDC when both measurements were available.

Based on these same concepts, IRM $_{\text {smoke }}$ can be calculated with a simple linear model assuming that IRM $_{255 \mathrm{~K}}$ is proportional to the IDC, as observed in the data, and that IRM plus a constant term due to meteoric smoke, which is also supported by data (Fig. 15). The model is written as:

$\mathrm{IRM}_{\mathrm{SP}}=\mathrm{IDC} \cdot m_{d}+\mathrm{IRM}_{\text {smoke }}$

$\mathrm{IRM}_{255 \mathrm{~K}}=\mathrm{IDC} \cdot m_{d}^{\prime}$

where $m_{d}^{\prime}$ is the dust $I_{R M_{255 K}}$ and $m_{d}$ is the dust IRM $M_{S P}$. These equations can be simplified and the IDC term removed from the calculation obtaining: 


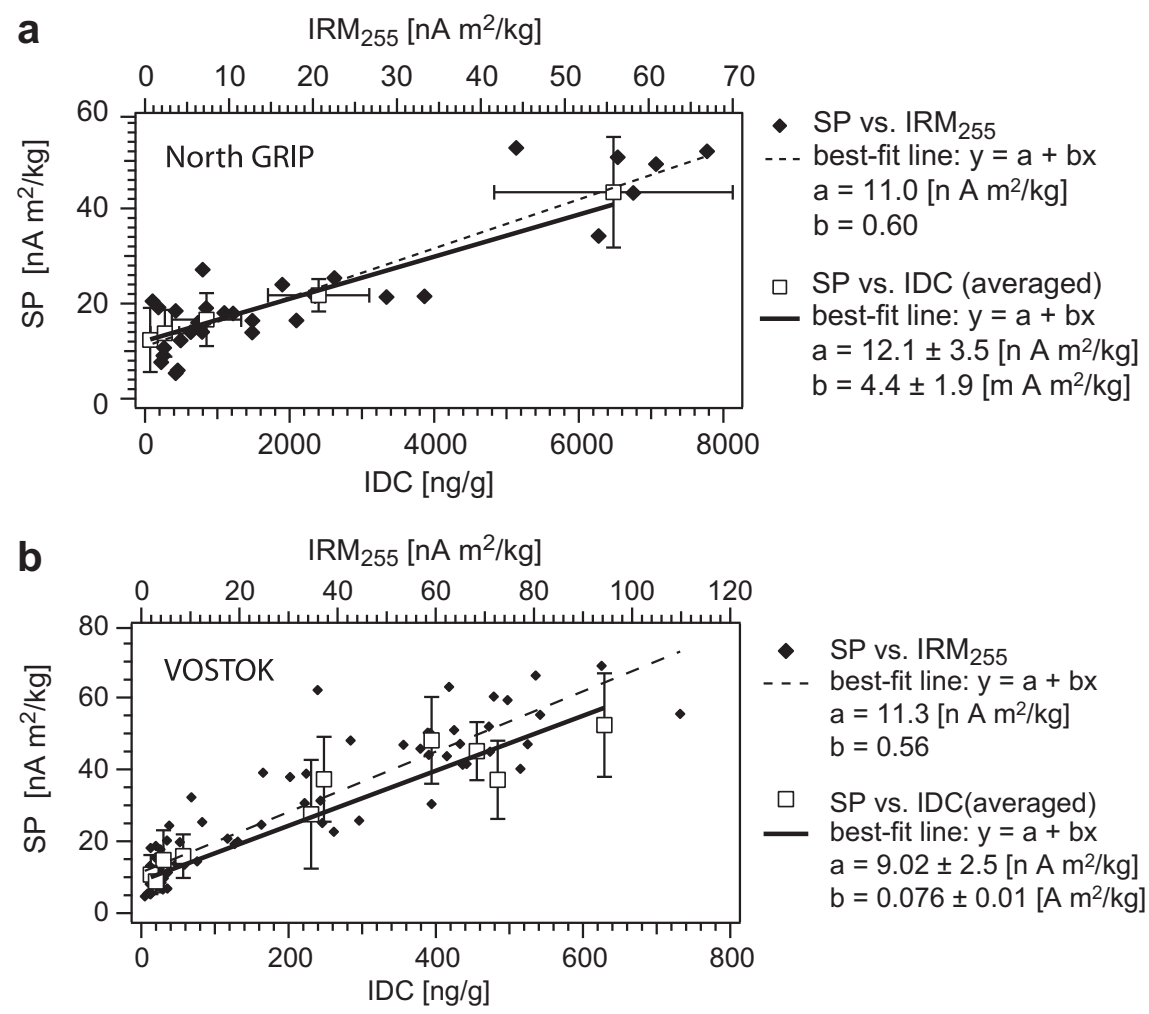

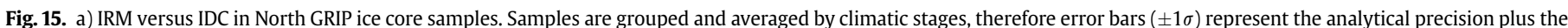

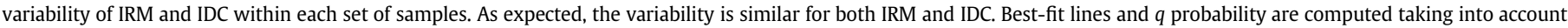

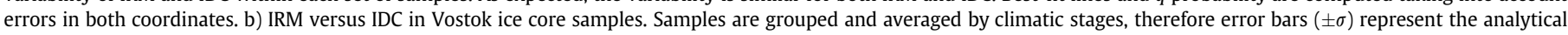
precision plus the variability of IRM within each set of samples. No errors are available for IDC. The probability $q>0.99$ for all linear fit.

$\mathrm{IRM}_{\mathrm{SP}}=\mathrm{IRM}_{\mathrm{smoke}}+\frac{m_{d}}{m_{d}^{\prime}} \mathrm{IRM}_{255 \mathrm{~K}} \cdot$

The linear model (eq. (1)) can be used to fit the IRM ${ }_{S P}$ and $I_{R M} M_{255}$ data in a least-squares sense, and to compute IRM ${ }_{\text {smoke }}$ and the ratio $m_{d} / m_{d}^{\prime}$ for the terrestrial dust without the need of IDC measurements. Results from North GRIP, Vostok and EPICA-Dome $C$ ice cores are shown in Table 2, data from EPICA-Dome $C$ were selected among samples with $H_{c r}$, ranging between 40.3 and $51.6 \mathrm{mT}$. All results are highly significant according to a Student $t$ test and, as expected, those from North GRIP and Vostok are similar to previously published calculations (Lanci and Kent, 2006; Lanci et al., 2007).

Our model (Eq. (1)) implicitly assumes that no major changes occur either in the $m_{d} / m_{d}^{\prime}$ ratio or in the dilution of meteoric smoke in the ice within the analyzed data set. The ratio $m_{d} / m_{d}^{\prime}$ may change as a consequence of different dust sources and indeed it changes between the different cores. However, we have ensured that the magnetic properties are sufficiently similar within each data set and the small uncertainty $(\sigma)$ obtained for $m_{d} / m_{d}^{\prime}$ substantiates this premise. The assumption of constancy of the meteoric smoke dilution is supported by the excellent fit to the linear model. The rather constant dilution during different climatic stages (in North

Table 2

$\mathrm{IRM}_{\text {smoke }}$ resulting from linear model, eq. (1)

\begin{tabular}{llll}
\hline & $\begin{array}{l}\mathrm{IRM}_{\text {smoke }} \pm 1 \sigma \\
\left(\mathrm{A} \mathrm{m}^{2} / \mathrm{kg}\right)\end{array}$ & $m_{d} / m_{d}^{\prime}$ & $\begin{array}{l}\text { Significance } \\
(t \text {-test })\end{array}$ \\
\hline North GRIP & $11.0 \pm 1.5 \times 10^{-9}$ & $0.60 \pm 0.054$ & $>99.9 \%$ \\
Vostok & $12.4 \pm 1.8 \times 10^{-9}$ & $0.55 \pm 0.042$ & $>99.9 \%$ \\
EPICA & $12.3 \pm 4.1 \times 10^{-9}$ & $0.94 \pm 0.23$ & $>95 \%$ \\
\hline
\end{tabular}

GRIP and Vostok ice cores), when the ice accumulation rate is known to change, hinders a climatic control on meteoric smoke deposition and supports the process of wet deposition for meteoric smoke, which does not depend on snow accumulation rate.

\subsection{Estimates of meteoric smoke concentration}

The concentration of meteoritic material can be estimated from magnetic measurements under the reasonable assumption that the large majority of iron contained in the ablated material is subject to high-temperature oxidation to magnetite during atmospheric entry. The average weight concentration of $\mathrm{Fe}$ in ordinary chondrites, which are the most common type of meteorites (Lodders and Fegley, 1998) and thus the principal source of meteoric smoke, ranges from $18 \%$ to $32 \%$ with an average of $23.8 \%$ (Wilkison and Robinson, 2000); CI chondritic composition for $\mathrm{Fe}$ is $19.04 \%$ (Anders and Grevesse, 1989). Using the average ordinary chondrite composition and assuming stoichiometric magnetite we expect a mass magnetization $\left(M_{S}\right)$ of meteoric smoke of $\sim 30 \mathrm{~A} \mathrm{~m}^{2} / \mathrm{kg}$ and a saturation remanence $M_{r}=M_{s} / 2 \approx 15 \mathrm{~A} \mathrm{~m}^{2} / \mathrm{kg}$. This estimate is compatible with $M_{r}$ measured in micrometeorites by (Suavet et al., 2009) and is used to estimate concentration of meteoric smoke and Fe in polar ice (Table 3 ).

The magnetic estimates of meteoritic Fe from North GRIP are virtually identical to chondritic Fe estimates based on chondritic Ir and Pt measurements made on the same site, which range from 0.12 to $0.24 \mathrm{ng} / \mathrm{g}$ (average $0.18 \mathrm{ng} / \mathrm{g}$ ) (Gabrielli et al., 2004).

Measurements of the concentration of Ir and Pt performed in Antarctica (Gabrielli et al., 2006) find a more complex situation with the presence of super-chondritic Ir/Pt ratio during interglacial periods, which was explained as a consequence of the fallout of 
Table 3

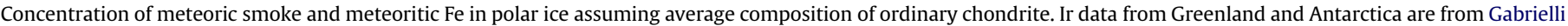
et al. (2004) and Gabrielli et al. (2006) respectively.

\begin{tabular}{|c|c|c|c|c|}
\hline & $\mathrm{IRM}_{\text {smoke }} \pm 1 \sigma\left(\mathrm{A} \mathrm{m}^{2} / \mathrm{kg}\right)$ & Smoke $\pm 1 \sigma(\mathrm{ng} / \mathrm{g})$ & $\mathrm{Fe} \pm 1 \sigma(\mathrm{ng} / \mathrm{g})$ & Chondritic Fe from Ir (ng/g) \\
\hline North GRIP & $11.0 \pm 1.5 \times 10^{-9}$ & $0.73 \pm 0.10$ & $0.17 \pm 0.024$ & $0.18 \pm 0.6$ \\
\hline Vostok & $12.4 \pm 1.8 \times 10^{-9}$ & $0.83 \pm 0.12$ & $0.20 \pm 0.029$ & $0.39 \pm 0.16$ \\
\hline Dome C & $12.3 \pm 4.1 \times 10^{-9}$ & $0.82 \pm 0.27$ & $0.19 \pm 0.064$ & $0.51 \pm 0.24^{\mathrm{a}}$ \\
\hline
\end{tabular}

${ }^{\text {a }}$ Not including the highly uncertain value dated at 22 kyrs BP.

a volcanic aerosol enriched in Ir and Pt (Vallelonga et al., 2010). The observed gradients between Dome $C$ and Vostok of the superchondritic mass ratios and of the Ir and Pt fluxes (Gabrielli et al., 2006) are in good agreement with the different dust magnetizations observed in EPICA-Dome $\mathrm{C}$ and Vostok ice samples, and consistent with a stronger influence on Dome $C$ of a nearby source of volcanic dust exposed or active during interglacial stages.

Measurements of glacial ice in Dome C and Vostok gave more reliable (chondritic) values of Ir and Pt with concentrations $1.1 \mathrm{fg} / \mathrm{g}$ and $1.5 \mathrm{fg} / \mathrm{g}$ in Vostok and Dome C respectively (Gabrielli et al., 2006). However even these concentrations are significantly larger than the mean value of $0.45 \mathrm{fg} / \mathrm{g}$ measured in North GRIP and the differences are further increased when fluxes are computed assuming dry deposition, because the snow accumulation rate on the East Antarctic plateau $\left(2.5 \mathrm{~g} \mathrm{~cm}^{-2} \mathrm{y}^{-1}\right.$ of water equivalent in Dome C) is about one order of magnitude smaller than in central Greenland ( $23 \mathrm{~g} \mathrm{~cm}^{-2} \mathrm{y}^{-1}$ of water equivalent in Summit).

Under our hypothesis of wet deposition for meteoric smoke, we expect similar concentration of chondritic Ir and Pt at all studied sites. We therefore re-examined the results from (Gabrielli et al., 2006) simply selecting samples with $\mathrm{Ir} / \mathrm{Pt} \leq 0.8$ to avoid samples with super-chondritic composition. As pointed out by Gabrielli et al. (2006) these samples belong to glacial periods and their average $\mathrm{Ir}$ concentration is $1.0 \pm 0.4 \mathrm{fg} / \mathrm{g}$ and $1.3 \pm 0.6 \mathrm{fg} / \mathrm{g}$ for Vostok and Dome C, respectively, corresponding to meteoritic Fe concentrations of $0.39 \pm 0.16 \mathrm{ng} / \mathrm{g}$ and $0.51 \pm 0.24 \mathrm{ng} / \mathrm{g}$, respectively. Although these concentrations are still higher that those obtained from magnetic measurements (Table 3) they are not completely incompatible especially considering that some influence of super-chondritic Ir is still possible. Further differences might arise from the grain-size distribution since magnetic measurements are restricted to a relatively narrow range of particle diameters whereas Ir and Pt measurements might include not only meteoric smoke but also smaller micrometeorites.

\section{Conclusions}

So far magnetic measurements have been performed successfully on ice core samples from central Greenland and East Antarctica. We believe the magnetic measurements have shown a good potential to investigate novel properties of aeolian dust directly in ice samples. These measurements are in fact nondestructive, they can be performed on small samples even with dust concentrations as small as a few ppb, allowing to estimate the contribution of aeolian dust including the smaller grain fraction which are not seen by Coulter counter measurements. Moreover, when IRM is combined with coercivity measurements it provides information on the dust provenance that can be used to complement geochemical analysis. Low temperature magnetic measurements revealed the presence of nano-meter sized Feoxides interpreted as meteoric smoke. Magnetic measurements of meteoric smoke concentration in ice are compatible with more conventional proxy measurements of platinum group elements and offer, for the first time, direct evidence of the range of grain size of meteoric smoke.

\section{Acknowledgments}

This work is a contribution to the PRIN 2009 research project "Variability and geographic provenance of eolian dust in Antarctica during the late Quaternary: a multi-parametric approach with the use of cutting-edge techniques". This research was initiated by support from grants (to LL, DK and PB) from the Office of Polar Programs of the U.S. National Science Foundation. The paper benefited of the suggestions from two anonymous reviewers. Lamont-Doherty Earth Observatory Contribution Nr. 7513.

\section{References}

Anders, E., Grevesse, N., 1989. Abundances of the elements: meteoritic and solar. Geochimica et Cosmochimica Acta 53, 197-214.

Basile, I., Grousset, F.E., Revel, M., Petit, J.R., Biscaye, P.E., Barkov, N.I., 1997. Patagonian origin of glacial dust deposited in east Antarctica (Vostok and dome c) during glacial stages 2, 4 and 6. Earth and Planetary Science Letters 146 (3-4), 573-589.

Bertotti, G., 1998. Hysteresis in Magnetism for Physicist, Material Scientists and Engineers. In: Academic Press Series in Electromagnetism. Academic Press, San Diego.

Biscaye, P.E., Grousset, F.E., Revel, M., Van der Gaast, S., Zielinski, G.A., Vaars, A. Kukla, G., 1997. Asian provenance of glacial dust (stage 2) in the Greenland ice sheet project 2 ice core, summit, Greenland. Journal of Geophysical Research 102 (26), 26765-26781.

Bory, A., Biscaye, P.E., Svensson, A., 2002. Seasonal variability in the origin of recent atmospheric mineral dust at Northgrip. Earth and Planetary Science Letters 196, 123-134.

Bory, A., Biscaye, P., Grousset, F., 2003. Two distinct seasonal Asian source regions for mineral dust deposited in Greenland (Northgrip). Geophysical Research Letters 30 (4). doi:10.1029/2002GL016446.

Bory, A., Wolff, E., Mulvaney, R., Jagoutz, E., Wegner, A., Ruth, U., Elderfield, H., 2010. Multiple sources supply eolian mineral dust to the Atlantic sector of coastal Antarctica: evidence from recent snow layers at the top of Berkner island ice sheet. Earth and Planetary Science Letters 291 (1-4), 138-148.

Brown, W.J., 1963. Thermal fluctuations of a single-domain particle. Physical Reviews 130 (5), 1677-1686.

Delmonte, B., Petit, J.-R., Maggi, V., 2002. Glacial to Holocene implications of the new 27000-year dust record from the EPICA Dome C (East Antarctica) ice core. Climate Dynamics 18 (8), 647-660. doi:10.1007/s00382-001-0193-9.

Delmonte, B., Petit, J.R., Basile-Doelsch, I., Jagoutz, E., Maggi, V., 2007. Late Quaternary Interglacials in East Antarctica from ice core dust records. In: Sirocko, F. Claussen, M., Sanchez-Goni, M., Litt, T. (Eds.), The Climate of Past Interglacials. Elsevier, Amsterdam, pp. 53-73.

Delmonte, B., Andersson, P.S., Hansson, M., Schoberg, H., Petit, J.R., Basile-Doelsch, I., Maggi, V., 2008. Aeolian dust in east Antarctica (EPICA-Dome C and Vostok): provenance during glacial ages over the last 800 kyr. Geophysical Research Letters L07703, 35.

Delmonte, B., Andersson, P.S., Schoberg, H., Hansson, M., Petit, J.R., Delmas, R. Gaiero, D.M., Maggi, V., Frezzotti, M., 2010. Geographic provenance of aeolian dust in East Antarctica during pleistocene glaciations: preliminary results from talos dome and comparison with east Antarctic and new Andean ice core data. Quaternary Science Reviews 29 (1-2), 256-264. doi:10.1016/j.quascirev.2009.05.010.

Deng, C., Zhu, R., Verosub, K., Singer, M., Vidic, N., 2004. Mineral magnetic properties of loess//paleosol couplets of the central loess plateau of china over the last 1.2 myr. Journal of Geophysical Research 109 (B01103).

Dunlop, D., 1973. Superparamagnetic and single-domain threshold sizes in magnetite. Journal of Geophysical Research 78, 1780-1793.

Dunlop, D., 1981. The rock magnetism of fine particles. Physics Earth Planetary Interiors 26, 1-26.

EPICA-Community-Members, 2004. Eight glacial cycles from an Antarctic ice core Nature 429, 623-628. doi:10.1038/nature02599.

Funaki, M., Sakai, H., 1991. Acquisition of natural remanent magnetization for dirt-snow containing rock dust. Journal of Geomagnetism and Geoelectricity 43, 803-811.

Funaki, M., 1998. Identification of cosmic dust in Antarctic ice by magnetic methods Geochemistry (in Japanese) 32, 225-232. 
Gabrielli, P., Barbante, C., Plane, J., Varga, A., Hong, S., Cozzi, G., Gaspari, V., Boutron, C., Cozzi, G, Gaspari, V., Planchon, FA, Cairns, W., Ferrari, C. Crutzen, P. Cescon, P. Boutron, C.F., 2004. Meteoric smoke fallout over the Holocene epoch revealed by iridium and platinum in Greenland ice. Nature 432, 1011-1014.

Gabrielli, P., Plane, J.M.C., Boutron, C., Hong, S., Cozzi, G., Cescon, P., Ferrari, C., Crutzen, P., Petit, J.-R., Lipenkov, V., Barbante, C., 2006. A climatic control on the accretion of meteoric and super-chondritic iridiumplatinum to the Antarctic ice cap. Earth and Planetary Science Letters 250, 459-469. doi:10.1016 j.epsl.2006.08.015.

Gabrielli, P., Petit, J.-R., Delmonte, B., De Deckker, P., Gaspari, V., Fischer, H., Ruth, U. Hong, S., Kriews, M., Boutron, C., Cescon, P., Barbante, C., 2010. A major glacial-interglacial change in aeolian dust composition inferred from rare earth elements in Antarctic ice. Quaternary Science Reviews 29 (1-2), 265-273.

Gaiero, D., Brunet, F., Probst, J.-L., Depetris, P., 2007. A uniform isotopic and chemical signature of dust exported from patagonia: rock sources and occurrence in southern environment. Chemical Geology 238 (1-2), 107-120.

Gaiero, D., 2007. Dust provenance in Antarctic ice during glacial periods: from where in southern South America? Geophysical Research Letters 34, L17707.

Genge, M.J., Grady, M.M., 1998. Melted micrometeorites from Antarctic ice with evidence for the separation of immiscible $\mathrm{Fe}-\mathrm{Ni}-\mathrm{S}$ liquids during entry heating. Meteoritics and Planetary Science 33 (2), 425-434

Genge, M.J., Engrand, C., Gounelle, M., Taylor, S., 2008. The classification of micrometeorites. Meteoritics and Planetary Science 43 (3), 497-515.

Grousset, F., Biscaye, P., Revel, M., Petit, J.-R., Pye, K., Joussaume, S., Jouzel, J., 1992. Antarctic (dome c) ice core dusts at 18 ky b.p.: isotopic constraints on origins and atmospheric circulation. Earth and Planetary Science Letters 111, 175-182.

Hamilton, W., Langway Jr., C., 1967. A correlation of microparticle concentrations with oxygen isotopes ratio in 700 years old Greenland ice. Earth and Planetary Science Letters 3, 363-366.

Helmer, M., Plane, J.M.C., Jun Qian, J., Gardner, C.S., 1998. A model of meteoric iron in the upper atmosphere. Journal of Geophysical Research 103 (D9), $10,913-10,926$

Hunten, D.M., Turco, R.P., Toon, O.B., 1980. Smoke and dust particles of meteoric origin in the mesosphere and stratosphere. Journal of Atmospheric Science 37, 1342-1357.

Jouzel, J., Masson-Delmotte, V., Cattani, O., Dreyfus, G., Falourd, S., Hoffmann, G., Minster, B., Nouet, J., Barnola, J., Chappellaz, J., Fischer, H., Gallet, J., Johnsen, S. Leuenberger, M., Loulergue, L., Luethi, D., Oerter, H., Parrenin, F., Raisbeck, G. Raynaud, D., Schilt, A., Schwander, J., Selmo, E., Souchez, R., Spahni, R. Stauffer, B., Steffensen, J., Stenni, B., Stocker, T., Tison, J., Werner, M., Wolff, E., 2007. Orbital and millennial Antarctic climate variability over the past 800,000 years. Science 317 (5839), 793-797.

Lambert, F., Delmonte, B., Petit, J.R., Bigler, M., Kaufmann, P.R., Hutterli, M.A., Stocker, T.F., Ruth, U., Steffensen, J.P., Maggi, V., 2008. New constraints on the aeolian dust cycle from an 800,000-year Antarctic ice core record. Nature 452, 616-619.

Lanci, L., Kent, D., 2006. Meteoric smoke fallout revealed by superparamagnetism in Greenland ice. Geophysical Research Letters 33 (L13308). doi:10.1029/ 2006GL026480.

Lanci, L., Kent, D., Biscaye, P.E., Bory, A., 2001. Isothermal remanent magnetization of Greenland ice: preliminary results. Geophysical Research Letters 28 (8) 1639-1642.

Lanci, L., Kent, D., Biscaye, P., Steffensen, J., 2004. Magnetization of Greenland ice and its relationship with dust content. Journal of Geophysical Research 109 (D09104). doi:10.1029/2003JD004433.

Lanci, L., Kent, D., Biscaye, P.E., 2007. Meteoric smoke concentration in the Vostok ice core estimated from superparamagnetic relaxation and some consequences for estimates of earth accretion rate. Geophysical Research Letters 34 (L10803). doi:10.1029/2007GL029811.

Lanci, L., Delmonte, B., Maggi, V., Petit, J., Kent, D., 2008a. Ice magnetization in the EPICA-Dome C ice core: implication for dust sources during glacial and interglacial periods. Journal of Geophysical Research 113 (D14207).

Lanci, L., Delmonte, B., Maggi, V., Petit, J.R., Kent, D., 2008b. Ice magnetization in the EPICA-Dome C ice core: preliminary results. Terra Antartica Reports 14, 83-88.

Langway, Jr., C.C., Oeschger,, H., Dansgaard,, W. (Eds.), 1985. Greenland Ice Core: Geophysics, Geochemistry and Environment. Geophysical Monographs, vol. 33. American Geophysics Union, Washington D.C.

Lodders, K., Fegley, B.J., 1998. The Planetary Scientist's Companion. Oxford University Press, New York, Oxford. ICE dust idp.

Love, S.G., Brownlee, D.E., 1991. Heating and thermal transformation of micrometeoroids entering the earths atmosphere. Icarus 89, 26-43.

Love, S.G., Brownlee, D.E., 1993. A direct measurement of the terrestrial mass accretion rate of cosmic dust. Science 262 (5133), 550-553.
Lupker, M., Aciego, S., Bourdon, B., Schwander, J., Stocker, T., 2010. Isotopic tracing ( $\mathrm{Sr}$, Nd, $\mathrm{U}$ and $\mathrm{Hf}$ ) of continental and marine aerosols in an 18th century section of the dye-3 ice core (Greenland). Earth and Planetary Science Letters 295 $(1-2), 277-286$

Moskowitz, B., Frankel, R., Walton, S., Dickson, D., Walton, K., Douglas, T., Mann, S., 1997. Determination of the preexponential frequency factor for superparamagnetic maghemite particles in magnetoferritin. Journal of Geophysical Research 102, 22,671-22,680.

Néel, L., 1955. Some theoretical aspects of rock magnetism. Philosophical Magazine (Supplement) 4 (14), 191.

Newell, A., Merrill, R., 2000a. Nucleation and stability of ferromagnetic states. Journal of Geophysical Research 105 (8), 19,377-19,391.

Newell, A., Merrill, R., 2000b. Size dependence of hysteresis properties of small pseudo-single-domain grains. Journal of Geophysical Research 105 (8), $19,393-19,403$.

Petit, J.R., Delmonte, B., 2009. A model for large glacial-interglacial climate-induced changes in dust and sea salt concentrations in deep ice cores (central Antarctica): palaeoclimatic implications and prospects for refining ice core chronologies. Tellus 61B, 768-790.

Petit, J., Jouzel, J., Raynaud, D., Barkov, N., Barnola, J.-M., Basile, I., Bender, M. Chappellaz, J., Davis, M., Delaygue, G., Delmotte, M., Kotlyakov, V., Legrand, M., Lipenkov, V., Lorius, C., Pepin, L., Ritz, C., Saltzman, E., Stievenard, M., 1999. Climate and atmospheric history of the past 420,000 years from the Vostok ice core, Antarctica. Nature 399, 429-436.

Revel-Rolland, M., De Dekker, P., Delmonte, B., Hesse, P., Magee, J., Basile-Doelsch, I., Grousset, F., Bosch, D., 2006. Eastern Australia: a possible source of dust in East Antarctica interglacial ice. Earth and Planetary Science Letters 249, 1-13.

Rietmeijer, F., 2001. Identification of Fe-rich meteoric dust. Planetary and Space Science 49, 71-77. ICE

Robertson, D., France, D., 1994. Discrimination of remanence-carrying minerals in mixtures, using isothermal remanent magnetisation acquisition curves. Physics of the Earth and Planetary Interiors 82, 223-234.

Ruth, U., Wagenbach, D., Steffensen, J., Bigler, M., 2003. Continuous record of microparticle concentration and size distribution in the central Greenland NGRIP ice core during the last glacial period. Journal of Geophysical Research 108 (D3), 4098. doi:10.1029/2002JD002376.

Sahota, J., Mayewski, P., Oldfield, F., Twickler, M.S., 1996. Magnetic measurements of Greenland and Himalayan ice-core samples. The Holocene 6 (4), 477-480.

Steffensen, J.P., 1997. The size distribution of microparticles from selected segments of the Greenland ice core project ice core representing different climatic periods. Journal of Geophysical Research 102, 26,755-26,763.

Suavet, C., Rochette, P., Gattaceca, J., Folco, L., 2008. Micrometeorites: a possible bias on the sedimentary magnetic record. Geochemistry Geophysics Geosystems 9 (11), Q11002.

Suavet, C., Gattaceca, J., Rochette, P., Perchiazzi, N., Folco, L., Duprat, J., Harvey, R., 2009. Magnetic properties of micrometeorites. Journal of Geophysical Research 114 (B04102).

Svensson, A., Biscaye, P., Grousset, F., 2000. Characterization of Lateglacial continental dust in the Greenland ice core project ice core. Journal of Geophysical Research 105 (4), 4637-4656.

Svensson, A., 1998. Characterization of Continental Dust in Greenland GRIP Ice Core Back to 44 Kyr BP. Ph.d., Univ. of Copenhagen.

Tauxe, L., 2002. Paleomagnetic Principles and Practice. In: Modern Approaches in Geophysics, vol. 17. Springer, New York.

Taylor, S., Lever, J.H., Harvey, R.P., 1998. Accretion rate of cosmic spherules measured at the south pole. Nature 392, 899-903.

Toppani, A., Libourel, G., Engrand, C., Maurette, M., 2001. Experimental simulation of atmospheric entry of micrometeorites. Meteoritics and Planetary Science 36 (10), 1377-1396.

Vallelonga, P., Gabrielli, P., Balliana, E., Wegner, A., Delmonte, B., Turetta, C., Burton, G., Vanhaecke, F., Rosman, K., Hong, S., Boutron, C., Cescon, P., Barbante, C., 2010. Lead isotopic compositions in the EPICA Dome C ice core and southern hemisphere potential source areas. Quaternary Science Reviews 29 (1-2), 247-255.

Wilkison, L.S., Robinson, S.M., 2000. Bulk density of ordinary chondrite meteorites and implications for asteroidal internal structure. Meteoritics and Planetary Science 35 (6), 1203-1213.

Winckler, G., Fischer, H., 2006. 30,000 years of cosmic dust in Antarctic ice. Science 313 (5786), 491

Winklhofer, M., Fabian, K., Heider, F., 1997. Magnetic blocking temperatures of magnetite calculated with a three-dimensional micromagnetic model. Journal of Geophysical Research 102 (B10), 22695-22709. 